\title{
THE EFFECT OF PUBLIC INSURANCE EXPANSIONS ON SUBSTANCE USE DISORDER TREATMENT: EVIDENCE FROM THE AFFORDABLE CARE ACT
}

\author{
Johanna Catherine Maclean \\ Brendan Saloner \\ Working Paper 23342 \\ http://www.nber.org/papers/w23342 \\ NATIONAL BUREAU OF ECONOMIC RESEARCH \\ 1050 Massachusetts Avenue \\ Cambridge, MA 02138 \\ April 2017
}

We thank Ioana Popovici, Douglas Webber, and Laura Wherry for helpful comments, and Steven Hill for data assistance. Brendan Saloner gratefully acknowledges funding from the National Institute on Drug Abuse (K01 DA042139). All errors are our own. The views expressed herein are those of the authors and do not necessarily reflect the views of the National Bureau of Economic Research.

NBER working papers are circulated for discussion and comment purposes. They have not been peer-reviewed or been subject to the review by the NBER Board of Directors that accompanies official NBER publications.

(C) 2017 by Johanna Catherine Maclean and Brendan Saloner. All rights reserved. Short sections of text, not to exceed two paragraphs, may be quoted without explicit permission provided that full credit, including $\odot$ notice, is given to the source. 
The Effect of Public Insurance Expansions on Substance Use Disorder Treatment: Evidence from the Affordable Care Act

Johanna Catherine Maclean and Brendan Saloner

NBER Working Paper No. 23342

April 2017

JEL No. I1,I13,I18

\title{
ABSTRACT
}

We examine Medicaid expansion under the Affordable Care Act (ACA) on substance use disorder (SUD) treatment utilization and financing. We couple administrative data on admissions to specialty SUD treatment and prescriptions for medications used to treat SUDs with a differences-in-differences design, comparing expanding and non-expanding states. Postexpansion, admissions did not significantly change in expanding states relative to non-expanding states. We find that in expanding states Medicaid insurance and use of Medicaid to pay for treatment increased by 13.9 percentage points (71\%) and 12.9 percentage points $(75 \%)$ following the expansion. Post expansion, Medicaid-reimbursed prescriptions for medications used to treat SUDs in outpatient settings increased by $43 \%$ in expanding states relative to non-expanding states. We find no statistically significant evidence that Medicaid expansions affected fatal alcohol poisonings or drug-related overdoses. Overall, our findings imply that ACA Medicaid expansion had a large impact on the financing of SUD treatment and medication receipt.

\author{
Johanna Catherine Maclean \\ Department of Economics \\ Temple University \\ Ritter Annex 869 \\ Philadelphia, PA 19122 \\ and NBER \\ catherine.maclean@temple.edu
Brendan Saloner
Department of Health Policy
and Management \\ Johns Hopkins Bloomberg School \\ of Public Health \\ 624 N. Broadway \\ Room 344 \\ Baltimore, MD 21205 \\ bsaloner@jhu.edu
}




\section{Introduction}

This study explores the effect of state Medicaid expansions under the Affordable Care Act (ACA) on substance use disorder (SUD) treatment utilization and financing among lowincome adults. This population has historically had little access to insurance but has elevated prevalence of SUDs (Busch, Meara et al. 2013). Medicaid is a publicly-funded insurance program for low-income individuals in the United States, but prior to the ACA many low-income adults were not eligible for the program. The ACA allocated funds for states to expand Medicaid to adults below $138 \%$ of the federal poverty level, but the decision to expand Medicaid was left optional for states. We leverage variation in Medicaid eligibility generated by U.S. states' decisions to expand Medicaid to these adults between 2010 and 2015 in our study.

Problems related to substance use are a major public health concern in the U.S. and other developed countries (World Health Organization 2017). In 2015, over 20 million individuals in the U.S. met diagnostic criteria for an SUD (Center for Behavioral Health Statistics and Quality 2015). Studying factors related to SUD treatment is of critical policy importance as the U.S. is the midst of an alarming and unprecedented drug overdose epidemic, largely related to opioids. Indeed, each day 91 U.S. residents die from an opioid overdose, a quadrupling of the death rate since 1999 (Centers for Disease Control and Prevention 2016).

SUDs are characterized by clinically significant impairment related to the use of alcohol or psychoactive drugs. Symptoms of impairment can include engaging in unintended risky behaviors, experiencing trouble in work or family settings due to substance use, and experiencing physical and psychological symptoms of withdrawal during periods of nonuse (Hasin, O'Brien et al. 2013). Furthermore, millions of Americans who do not meet diagnostic criteria for SUDs engage in high-risk behaviors such as binge and/or heavy drinking, or 
nonmedical use of prescription drugs (Center for Behavioral Health Statistics and Quality 2016). ${ }^{1}$ Indeed, recent research suggests that the harms related to substance may contribute to declining life expectancy among middle aged white Americans (Case and Deaton 2015).

In addition to personal costs borne by the affected individual, substance use also contributes to a wide range of expensive social problems including elevated healthcare utilization (Balsa, French et al. 2009, French, Fang et al. 2011, Mark, Yee et al. 2016), crime and violence (Markowitz and Grossman 2000, Carpenter 2005), increased use of social services (Jayakody, Danziger et al. 2000), traffic accidents (Anderson, Hansen et al. 2013), and reduced productivity in the labor market (Terza 2002). Indeed, the annual social costs of alcohol and drug use on the U.S. economy are estimated at \$519B (Caulkins, Kasunic et al. 2014). ${ }^{2}$

While the effectiveness and cost-effectiveness of SUD treatment is well-established (Rajkumar and French 1997, Lu and McGuire 2002, National Institute on Drug Abuse 2012, Popovici and French 2013, Swensen 2015), only one-tenth of individuals who meet the diagnostic criteria for SUDs receive treatment in any year (Center for Behavioral Health Statistics and Quality 2016). Although there are myriad reasons for failure to receive treatment, key barriers to receiving treatment include lack of insurance coverage and inability to pay (Center for Behavioral Health Statistics and Quality 2016).

The ACA provides an opportunity to increase treatment use among individuals with SUD and to alter the financing of such treatment; in particular to better integrate the historically

\footnotetext{
${ }^{1}$ Binge drinking is defined by the U.S. Centers for Disease Control and Prevention as five (four) or more drinks in one drinking sessions for men (women). This organization defines heavy drinking as two (one) or more drinks per day among men (women) (https:/www.cdc.gov/alcohol/; accessed February 22 ${ }^{\text {nd }}, 2017$ ). Non-medical use of prescription drugs is defined as the use of these medications without a prescription from a healthcare provider, use in a manner other than as directed (e.g., taking a higher dosage than prescribed), or use only for the medication's psychotropic experience (e.g., euphoria, sedation) (United Nations Office on Drugs and Crime 2011).

2 This estimate is inflated by the authors from the original estimate of $\$ 481 \mathrm{~B}$ (with $\$ 255 \mathrm{~B}$ attributable to alcohol and \$226B attributable to psychoactive drugs) in 2011 dollars to 2017 dollars using the Consumer Price Index.
} 
isolated SUD treatment delivery system into insurance payment. Medicaid expansion provides millions of previously uninsured adults with coverage, and SUD treatment is a required benefit in expansion plans (Beronio, Glied et al. 2014). Due in large part to the substantial increases in the number of covered individuals and services, healthcare scholars argue that 'no illness will be more affected than substance use disorders' by the ACA (McLellan and Woodworth 2014).

We study the effects of Medicaid expansion under the ACA on treatment utilization and use of Medicaid as source of payment for such treatment. We leverage administrative data drawn from the Treatment Episodes Data Set (TEDS) between 2010 and 2015, and the Medicaid State Drug Utilization Data (SDUD) between 2011 and 2015. TEDS includes over ten million admissions to specialty SUD treatment facilities while SDUD captures all prescriptions for medications purchased at retail and online pharmacies used to treat SUDs in outpatient settings for which Medicaid is a third-party payer. We couple these administrative data sets with differences-in-differences regression models.

Our findings suggest that states expanding Medicaid experienced no change in admissions to specialty SUD treatment post-expansion relative to non-expanding states. Among patients receiving specialty treatment, Medicaid insurance coverage increased 13.2 percentage points (71\%) and use of Medicaid as a form of payment increased by 12.9 percentage points (75\%) in expanding states relative to non-expanding states, post expansion. Our relative effect size estimates are large as Medicaid played a modest role in the financing of SUD treatment prior to the ACA: in expansion states only $19 \%$ of patients had Medicaid coverage and just $17 \%$ used Medicaid to pay for treatment in the pre-expansion period. Medicaid coverage increases were almost entirely offset by reductions in the uninsured rate among patients receiving specialty care, 
and Medicaid payment largely offset payments made by state and local governments. Thus, our analysis does not suggest that Medicaid expansions led to large crowd out of private insurance.

Post-expansion, prescriptions for medications used to treat SUDs in outpatient settings financed by Medicaid increased by $43 \%$ in expanding states relative to non-expanding states. In a supplementary analysis, we examine changes in fatal alcohol poisonings and drug-related overdoses from 2010 to 2015 . We do not find any statistically significant evidence of changes in such deaths within expansion states relative to non-expansion states in the post-expansion period.

\section{The Medicaid program, a conceptual framework, and prior research}

We next discuss the Medicaid program within the context of the ACA, review a conceptual framework that motivates an economic study of public insurance expansions on demand for SUD treatment, and briefly review the related literature on Medicaid expansions.

\subsection{Medicaid expansion under the ACA}

The ACA expanded Medicaid eligibility to virtually all individuals with incomes below $138 \%$ of the poverty level. Before the ACA, Medicaid was only available to specific categories of low-income individuals and state income eligibility criteria varied widely. As a result, many low-income individuals with substantial health needs were not eligible for Medicaid (Decker, Kostova et al. 2013). Pre-ACA simulations indicated that the prevalence of SUDs was substantially higher in the population targeted by Medicaid expansions and that unmet need was higher within this group than populations previously eligible (Busch, Meara et al. 2013).

The ACA Medicaid expansion was designed as a national program that would provide enhanced federal funding for all states to cover the newly eligible populations (French, Homer et al. 2016). However, the 2012 Supreme Court decision on the ACA left Medicaid expansions 
optional to the state. ${ }^{3}$ Just half the states and DC initially participated in the Medicaid expansion in 2014, although by 2017, 32 states (including DC) had expanded their program.

\subsection{Conceptual framework}

Insurance, by lowering the out-of-pocket price faced by consumers, is predicted to increase the quantity of healthcare services demanded. Correspondingly, the Medicaid expansions we study should, all else equal, increase the quantity of SUD treatment demanded. However, there are several factors unique to the patients potentially seeking SUD treatment and the providers delivering such care that may modify the predicted increases in quantity demanded.

On the demand side, individuals may delay seeking, or choose not to seek, SUD treatment for reasons other than insurance coverage and ability to pay for treatment. Unlike most healthcare services, a large amount of SUD treatment is received under legal coercion, for example, treatment ordered by a judge as an alternative to jail time (Substance Abuse and Mental Health Services Administration 2016). Legally coerced treatment is less likely to be driven by insurance coverage than by non-economic factors such as the criminal justice system. Additionally, SUD treatment has historically been heavily supported by state and local government funding grants, allowing patients with limited financial resources to receive care for free or at a heavy discount. In 2009 (thus in advance of ACA implementation), 52\% of specialty SUD treatment facilities reported offering free treatment to patients who could not pay and $62 \%$ offered sliding scale discounts (Substance Abuse and Mental Health Services Administration 2010). ${ }^{4}$ This form of charity care can act as substitute for paid care (Lo Sasso and Meyer 2006) and may mute the effect of Medicaid expansions.

\footnotetext{
${ }^{3}$ National Federation of Independent Business v. Sebelius, 567 U.S.
} (2012), 183 L. Ed. 2d 450, 132 S.Ct. 2566. 
Having insurance could increase an individual's propensity to engage in substance use. One hypothesis is that insurance insulates people from the full costs of substance use, thereby potentially encouraging such behavior (i.e., ex ante moral hazard). However, to the best of our knowledge, there is no evidence of ex ante moral hazard following the ACA-related Medicaid expansions (Courtemanche, Marton et al. 2017a, Simon, Soni et al. 2017). Gaining insurance could also increase substance use due through income effects and/or easier access to lower-cost addictive medications such as opioids, stimulants, and benzodiazepines.

On the supply side, capacity and financial constraints within the specialty SUD treatment delivery system (Andrews, Abraham et al. 2015) may limit the ability of providers to meet the increases in the quantity of care demanded, at least in the short run. That is, many SUD treatment facilities may not have any open slots to which they can admit patients (McLellan and Meyers 2004, Carr, Xu et al. 2008, Jones, Campopiano et al. 2015). Gaining access to SUD treatment in a private doctor's office may also be challenging for those who gain Medicaid coverage. While the number of primary care physicians willing to see Medicaid patients has grown under the ACA, Medicaid acceptance continues to lag behind private insurance among such providers (Polsky, Candon et al. 2017).

Based on the preceding considerations, we test the following hypotheses in our analysis. Following Medicaid expansion we expect:

H1: More individuals will receive treatment (both specialty treatment and prescriptions used in outpatient settings) in expanding states relative to non-expanding states.

H2: More patients in specialty SUD treatment will have Medicaid insurance and use Medicaid to pay for treatment in expanding states relative to non-expanding states. 
While we expect these changes to occur in response to Medicaid expansion, the magnitude of these effects if an open question.

\subsection{Prior literature}

A growing literature examines the effects of the ACA-related Medicaid expansions on insurance coverage, general healthcare use, and health outcomes (Antonisse, Garfield et al. 2016, French, Homer et al. 2016, Courtemanche, Marton et al. 2017b). For example, Wherry and Miller (2016) show that, post-expansion, Medicaid coverage increased by 10.5 percentage points (34\%) among U.S. residents 19-64 years of age with family incomes below $138 \%$ of the federal poverty level while uninsurance declined 7.4 percentage points $(22 \%)$.

Several studies document that ACA-related Medicaid expansion is associated with improvements in access to general healthcare services such as primary care visits among lowincome adults in expanding states versus non-expanding states (Kirby and Vistnes 2016, Mulcahy, Eibner et al. 2016, Sommers, Blendon et al. 2016b, Wherry and Miller 2016, Miller and Wherry 2017, Simon, Soni et al. 2017). There is less decisive evidence as to whether the ACA-related Medicaid expansion improved health status. Two studies suggest improvements in some measures of health (Sommers, Blendon et al. 2016a, Simon, Soni et al. 2017) while a third suggests that these expansions had no substantial effect (Courtemanche, Marton et al. 2017a).

The literature on the ACA-related Medicaid expansions and receipt of SUD treatment is small. To our knowledge, only two prior clinical studies have examined changes in SUD treatment following the ACA Medicaid expansion. Saloner, Bandara et al. (2017), using the National Survey on Drug Use and Health, find not change in SUD treatment between 2010-2013 (pre-expansion) and 2014 (post-expansion), but do find that Medicaid paid for a larger share of treatment in 2014. While this is the first study to consider a broad array of SUD-related 
treatment outcomes, it is purely descriptive in nature and cannot establish the contribution of

Medicaid expansion to changes in use observed after 2014. Wen, Hockenberry et al. (2017) use the Medicaid State Drug Utilization Data (SDUD) - the same dataset we examine in our prescription drug analysis - to test changes in use of buprenorphine between expansion and nonexpansion states through 2014. The authors find a 70\% increase in the volume of buprenorphine prescriptions reimbursed by Medicaid in expansion states compared to non-expansion states. ${ }^{5}$ While the Wen et al study is clearly important, it focuses on a single substance of abuse (opioids) and a single treatment modality (buprenorphine received in an outpatient setting).

\section{Data, variables, and methods}

\subsection{Data on specialty SUD treatment: Treatment Episode Data Set (TEDS)}

We use the Treatment Episode Data Set (TEDS) to study specialty SUD treatment. TEDS is an administrative database compiled annually by the U.S. Substance Abuse and Mental Health Services Administration (SAMHSA) in collaboration with state substance abuse agencies. SAMHSA defines a specialty SUD treatment facility as a hospital, a residential SUD facility, an outpatient SUD treatment facility, or other facility with an SUD treatment program that offers:

(i) outpatient, inpatient, or residential/rehabilitation SUD treatment; (ii) detoxification treatment; (iii) opioid treatment; or (iv) halfway-house services that include SUD treatment.

TEDS is one component of a broader data inventory maintained by SAMHSA to track the quantity and quality of specialty SUD treatment within the U.S. The TEDS includes information

\footnotetext{
5 The potential impact of the ACA Medicaid expansions may also be gleaned from prior state-level expansions of Medicaid eligibility. In the decade prior to the ACA, several states sought federal waivers to provide Medicaid to otherwise ineligible low-income adults (Rudowitz, Artiga et al. 2014). These expansions generally restricted eligibility to very low-income individuals and some expansions covered only a limited set of benefits (Bouchery, Harwood et al. 2012). Overall, these expansions did not result in widespread reductions in the uninsured rate. In two studies Wen and colleagues (Wen, Hockenberry et al. 2014, Wen, Druss et al. 2015) examine the impact of preACA Medicaid eligibility under these waiver-based expansions. The authors find that expansions decreased unmet need for SUD treatment and increased specialty SUD treatment admissions.
} 
on approximately two million admissions to specialty SUD treatment each year, and contains nearly the universe of specialty SUD treatment facilities that receive financing from the state or federal government, are certified by the state to provide specialty SUD treatment, or are tracked for some other reason. ${ }^{6}$ Thus, TEDS reflect admissions financed by multiple payers (e.g., selfpayment, private insurance, Medicaid, Medicare). TEDS is commonly employed within the policy literature to study SUD treatment (Anderson 2010, Dave and Mukerjee 2011, Pacula, Powell et al. 2015, Powell, Pacula et al. 2015) and is used by the Federal government to estimate the costs of SUD treatment to the U.S. economy (Office of National Drug Control Policy 2012). While TEDS is not a national probability sample, patients receiving treatment in TEDStracked facilities are representative of the broader specialty SUD treatment-receiving population. For example, demographics of patients in TEDS-tracked facilities are comparable to samples of individuals who report past year SUD treatment in the NSDUH (Gfroerer, Bose et al. 2014).

We exclude admissions for which the patient is less than 18 years of age as such admissions are not directly affected by the Medicaid expansions we study, which target adults. ${ }^{7}$ A limitation of the TEDS is that not all states report data in each year. Appendix Table 1 reports the states not providing data to TEDS in each year 2010-2015. This number ranges from one to five states, thus the TEDS captures the vast majority of states in all years of our study. ${ }^{8}$

\subsection{Data on prescription medications: State Drug Utilization Data (SDUD)}

An objective of the ACA is to facilitate integration of SUD treatment into general healthcare, for example, providing outpatient treatment in physicians' offices (McLellan and

\footnotetext{
${ }^{6}$ TEDS does not include treatment received in private physician's offices, facilities that do not receive any public funding, emergency departments, and self-help groups.

${ }^{7}$ The oldest age category in TEDS is 55 years and above. Thus, we cannot exclude those patients over 64 years who are also not directly targeted by the expansions that we study here. However, admissions among those 55 years and older represent less than $5 \%$ of the TEDS admissions.

${ }^{8}$ We re-estimated our regression models on the unbalanced sample of states. Results are not appreciably different from results based on the unbalanced panel. Please see Supplementary Tables 1A, 1B, and 1C.
} 
Woodworth 2014). Such care is not captured in the TEDS, which includes specialty care only. To provide broader insight into the effect of Medicaid expansions on SUD treatment utilization that may occur in office-based settings, we turn to the SDUD. Studying medication treatment prescribed by outpatient physicians may also allow us to measure the extent to which newly insured individuals who have SUDs are forming relationships with healthcare providers and becoming integrated with the general healthcare delivery system. Given the historical segregation of SUD treatment from general healthcare (Buck 2011), such integration is important for treating overall health and, in turn, patient wellbeing. Finally, demand response may be stronger for treatment offered in primary care settings such as physician offices, where prescription medications are generally obtained, and outside the specialty system that we capture in TEDS. Primary care settings are often thought to be more appealing to patients who are reluctant to seek specialty SUD treatment, but may be willing to receive care in a mainstream primary care setting (Boone, Brown et al. 2004).

The SDUD includes all states' data for outpatient prescription medications covered under the Medicaid Drug Rebate Program (U.S. Department of Health and Human Services 2012). Since 1992, state Medicaid programs have been compelled to submit data on the number and type of prescriptions filled each quarter to the Centers for Medicare \& Medicaid Services (CMS) in exchange for federal matching funds. We use data from 2011 to 2015 in our study and aggregate the SDUD to the state-year level. ${ }^{9}$

\footnotetext{
${ }^{9}$ SDUD includes the universe of prescriptions purchased in retail and online pharmacies for which Medicaid, at least partially, financed the prescription in the Medicaid fee-for-service (FFS) program beginning in 1992. Beginning in March 2010, Medicaid managed care (MC) program prescriptions were included in the database following implementation of the Medicaid Prescription Drug Rebate Equalization Act of 2009. Therefore, we exclude years prior to 2011 as we have incomplete information on MC prescriptions. However, we have included 2010 in supplementary analyses (see Supplementary Table 2). We have also excluded five states (AZ, HI, OH, RI, and VA) that display odd missing data patterns (see Supplementary Table 3). Finally, we have analyzed the SDUD data at the annual, rather than quarter, level (see Supplementary Table 4). These changes to do not alter our results
} 
We focus on medications approved by the Food and Drug Administration (FDA) for the treatment of SUDs: buprenorphine, naltrexone, acamprosate, disulfiram, and topiramate. ${ }^{10} \mathrm{We}$ do not include methadone, a standard treatment for opioid use disorder, as methadone purchased through a pharmacy is typically utilized to treat chronic pain (Office of the Inspector General Commonwealth of Massachusetts 2016). We also exclude buprenorphine formulations that are indicated for pain management rather than opioid use disorder (Wen, Hockenberry et al. 2017).

\subsection{Medicaid expansion data}

We rely on data from the Kaiser Family Foundation ${ }^{11}$ and Sommers, Arntson et al. (2013) to construct our Medicaid expansion variables. Table 1 reports expanding states and the associated expansion date. The majority of expanding states implemented their expansion on January $1^{\text {st }}, 2014$, coinciding with the availability of enhanced federal funding under the ACA. Six states (California, Connecticut, DC, New Jersey, Minnesota, and Washington) expanded under ACA provisions prior to 2014; we refer to these states as 'early expanding states'. ${ }^{12}$ Two states expanded Medicaid later in 2014 (Michigan and New Hampshire). In addition, five states expanded in 2015 or 2016 (Alaska, Indiana, Louisiana, Montana, and Pennsylvania); we refer to these states as 'late expanding states'. States that expanded Medicaid after December $31^{\text {st }}, 2015$ do not offer variation in our empirical models.

\footnotetext{
in a meaningful way. We explored whether Medicaid expansion predicted the probability of the above-noted missing data pattern and we found no evidence of any relationship. See Supplementary Table 5.

${ }^{10}$ https://www.drugabuse.gov/publications/drugfacts/treatment-approaches-drug-addiction (accessed February $17^{\text {th }}$, 2017). We also consider branded versions of these generic drugs.

${ }^{11} \mathrm{http}$ ://kff.org/health-reform/state-indicator/state-activity-around-expanding-medicaid-under-the-affordable-careact/?currentTimeframe $=0$ (accessed December $\left.20^{\text {th }}, 2016\right)$.

${ }^{12}$ Under the ACA statute, the federal government would provide $100 \%$ of the matching funds beginning in 2014 to states expanding Medicaid (this amount gradually decreases in subsequent years). The early expansion states received the full federal match in 2014, but for years prior to 2014 had to contribute their state's typical match rate. http://kff.org/medicaid/issue-brief/understanding-how-states-access-the-aca-enhanced-medicaid-match-rates/ (accessed March $\left.4^{\text {th }}, 2017\right)$.
} 
TEDS provides data annually and the specific date on which an admission occurred is unknown to researchers. For Medicaid expansions that occur within a year, we assign the expansion to a state based on the share of the year for which the expansion is in place. ${ }^{13}$ In the SDUD, which are provided at the state-quarter-level, we match expansions to the closest quarter.

\subsection{Outcome variables}

We consider several outcome variables in our analysis of the effect of state Medicaid expansions on SUD treatment utilization and financing. These variables necessarily differ across our two datasets. First, we consider the number of admissions to specialty SUD treatment in the TEDS. ${ }^{14}$ To construct the admissions measure, we convert the number of admissions to the rate per 100,000 persons in a state age 18 to 64 years (the population targeted by the expansions to newly eligible adults that we study here, see Frean, Gruber et al. (2017)) using population data from the American Community Survey (ACS) (Flood, King et al. 2017) and the University of Kentucky Center for Poverty Research Center (2016). ${ }^{15}$ Second, we consider the patient's source of insurance in the TEDS: private insurance, Medicaid insurance, other insurance (e.g., Medicare, Veteran's Health Administration), and uninsured. Third, regardless of what insurance the patient may have, we consider the source of payment that is expected to finance the majority of a patient's treatment in the TEDS: private insurance, Medicaid insurance, self-payments, or states and localities (this source also includes care provided for free and 'other' payment). This final payment captures safety net programs that are paid for outside of insurance and patients

\footnotetext{
${ }^{13}$ We have also applied alternative coding schemes: (i) using a coding scheme proposed by Maclean, Pesko et al. (2017) and (ii) excluding DC, DE, MA, NY, and VT from the analysis sample following Wherry and Miller (2016); these states that covered adults below $100 \%$ of the federal poverty level before the ACA. Results are not appreciably different from those reported in the manuscript. See Supplementary Tables 6A, 6B, 6C, and 6D.

${ }^{14}$ The term 'admission' is used in the TEDS to broadly refer to the initiation of any new treatment in a particular setting. Admissions in the TEDS thus encompass services received in both inpatient and outpatient settings (where treatment is sometimes referred to as an 'encounter' rather than an 'admission').

${ }^{15}$ We first construct the share of the population that is 18 to 64 years from the ACS and second we multiply this number by a state's total population.
} 
paying out of pocket. Facilities can receive more than one type of payment; the TEDS defines the primary payer as whichever entity supports the greatest share of the cost of treatment. ${ }^{16}$ As noted earlier in the manuscript, many SUD treatment providers do not accept insurance of any type. Thus, examining whether newly acquired insurance can be used to pay for SUD treatment by patients is important to understanding whether or not expansions in fact reduce the costs of treatment for patients (Saloner, Akosa Antwi et al. 2017).

Both the patient insurance status and payment source variables that we study are only available for a subset of states (Substance Abuse and Mental Health Services Administration 2017). Moreover, several states have substantial missing data in these variables. We retain only states that have less than $25 \%$ missing data in all years of the analysis period (2010-2015) to form our insurance and payment analysis samples (results are robust to alternative thresholds for missing data, e.g., 15\%). ${ }^{17}$ After applying this exclusion criterion, we have 29 states in our insurance state sample and 25 states in our payment state sample. The specific states in these samples are listed in Appendix Table 2.

A concern with our analyses of these samples is that they may not reflect the experiences of the full set of U.S. states, thus calling to question the generalizability of our findings. To explore this issue to some extent, we compare demographics from the ACS for (i) admission sample states, (ii) insurance sample states, and (iii) payment sample states. Results are reported

\footnotetext{
${ }^{16}$ Payer source is documented in the TEDS with the following item: 'Identifies the primary source of payment for this treatment episode. Guidelines: States operating under a split payment fee arrangement between multiple payment sources are to default to the payment source with the largest percentage. When payment percentages are equal, the State can select either source.' This variable does not allow us to capture payment source with ideal accuracy. For example, we are unable to measure patients who use multiple payment sources to pay for treatment. We note our inability to accurately study the use of multiple payments as a limitation of this study.

${ }^{17}$ See Supplementary Tables 7A and 7B.
} 
in Appendix Table 3 and suggest that, at least across these observable characteristics, the insurance and payment states samples are similar to states in admission states sample. ${ }^{18}$

In terms of prescription medications used to treat SUDs in outpatient settings that are measured in the SDUD, we consider the number of prescriptions each year per 100,000 persons in a state among residents 18 to 64 years of age.

\subsection{Control variables}

SUD treatment utilization is determined by myriad factors. Ideally, we would like to include variables in our regression models that are plausibly linked with both our outcomes and to the probability that a state expands its Medicaid program with the ACA, and therefore reduce omitted variable bias in our coefficient estimates. To this end, we merge state-level information from several sources into the TEDS and SDUD.

Specifically, we merge in annual state-level data on demographics from the ACS: average age, sex, race and Hispanic ethnicity, educational attainment, marital status, urbanicity, disabled, ${ }^{19}$ and foreign born. We also merge in the annual unemployment rate from the Bureau of Labor Statistics Local Area Unemployment Database from the University of Kentucky Center for Poverty Research Center (2016).

We control for social policies that may reflect state attitudes toward the welfare of lower income populations (maximum monthly benefit for a family of four for the Supplemental

\footnotetext{
${ }^{18}$ An additional, and perhaps more concerning issue from a bias standpoint, is that the Medicaid expansions that we study may have influenced whether a state reported insurance or payment information to SAMHSA and/or the degree of missingness in these variables. Either of these scenarios could lead to conditional-on-positive bias in our regression coefficient estimates (Angrist and Pischke 2009). To explore this possibility, we regress the probability that a state has more than $25 \%$ missing in any given year in the insurance variable and the payment variable.

Results do not suggest that the Medicaid expansions affected these variables, which provides some evidence that our analyses of the insurance and payment variables are not vulnerable to conditional-on-positive bias. See Supplementary Table 8.

${ }^{19}$ More specifically, a cognitive, ambulatory, independent living, self-care, vision, and/or hearing disability. This variable proxies for a state's underlying health status.
} 
Nutrition Assistance Program and Temporary Aid for Needy Families) and an indicator for whether the Governor is a Democrat (University of Kentucky Center for Poverty Research Center 2016). ${ }^{20}$ Finally, we link state population 18 to 64 years of age (we do not control for population in the rate regressions as population is in the denominator of our outcome variables).

\subsection{Empirical model}

We estimate the differences-in-differences (DD) regression outlined in Equation (1):

$$
S U D_{s t}=\alpha_{0}+\alpha_{1} \text { Expand }_{s t}+\alpha_{2}^{\prime} X_{s t}+S_{s}+\tau_{t}+\varepsilon_{s t}
$$

$S U D_{s t}$ is an SUD treatment outcome in state $s$ in time t. Expand $s t$ is an indicator for whether or not a state has expanded its Medicaid program. $X_{s t}$ is a vector of state level characteristics. $S_{s}$ and $\tau_{t}$ are vectors of state and year fixed effects. Inclusion of state fixed effects allows us to control for time-invariant state-level factors that are unobservable (to the econometrician) and implies that our regression models are identified off within-state variation in Medicaid expansions. Year fixed effects control for secular trends in SUD treatment utilization and financing that affect the nation as a whole. $\varepsilon_{s t}$ is the error term. Because the SDUD is provided by CMS at the quarterly level, we replace year fixed effects with quarter-year ('period') fixed effects in our analyses of this data set.

We estimate regression models using unweighted OLS. ${ }^{21}$ We cluster standard errors around the state (Bertrand, Duflo et al. 2004). However, we applied the wild cluster bootstrap (Cameron and Miller 2015) in our insurance and payment regressions, as we have just 29 clusters in the insurance state sample and 25 clusters in the payment state sample. Results are comparable to our main analysis. ${ }^{22}$

\footnotetext{
${ }^{20}$ We treat the mayor of DC as the de facto Governor of this jurisdiction following Maclean and Saloner (2017).

${ }^{21}$ When our outcome is binary, this model is a linear probability model.

${ }^{22}$ See Supplementary Tables 9A and 9B.
} 


\subsection{Validity of the research design}

A necessary assumption for the DD model to recover causal estimates is that the treatment (i.e., states expanding Medicaid) and the comparison (i.e., states not expanding Medicaid) groups would follow the same trend in the post-treatment period, had the treatment states not been treated. However, this assumption is inherently untestable since the counterfactual trend is not observed for the treatment group. We instead attempt to provide suggestive evidence on this assumption. To this end, we proceed in two ways.

First, we examine unadjusted trends in the pre-treatment period in our outcome variables for the treatment and comparison groups. If we find that the outcomes appear to trend similarly in the pre-treatment period across these groups, such trends provide suggestive evidence that our TEDS and SDUD data satisfy the parallel trends assumption. Second, using the pre-treatment data only, we estimate regression models similar to Equation (1), except that we replace the DD variable with an interaction between the treatment group and a linear time trend (Akosa Antwi, Moriya et al. 2013). This regression model is outlined in Equation (2):

$$
S U D_{s t}=\gamma_{0}+\gamma_{1} \text { Treat }_{s} * \text { Time }_{t}+\gamma_{2}^{\prime} X_{s t}+S_{s}+\tau_{t}+\mu_{s t}
$$

If we cannot reject the null hypothesis that $\gamma_{1}$ is zero, then this finding provides further support that our datasets satisfy the parallel trends assumption. We exclude early expanding states.

\section{Results for specialty SUD treatment in the Treatment Episode Data Set}

\subsection{Summary statistics: TEDS}

Table 2 reports summary statistics for expanding states in their pre-expansion years (Table 1) and non-expanding states 2010-2013. The mean number of annual admissions per 100,000 adults 18 to 64 years was 1,062 in expanding states and 841 in non-expanding states. Among patients receiving specialty SUD treatment in expanding states, $11.4 \%$ held private 
insurance, $18.6 \%$ Medicaid, $10.9 \%$ other insurance (e.g., Medicare), and 59.1\% held no insurance (i.e., uninsured) at admission to treatment. For individuals in non-expanding states, the same percentages were $6.3 \%, 15.7 \%, 7.7 \%$, and $70.3 \%$, respectively.

In terms of the forms of primary payment patients receiving specialty SUD treatment used to finance care, $8.7 \%$ and $17.3 \%$ used private insurance and Medicaid insurance, while $21.8 \%$ self-paid and $52.1 \%$ relied on state and local governments, respectively. In nonexpansion states the share with each source of payment was: $3.6 \%$ private insurance, $8.3 \%$ Medicaid insurance, $18.9 \%$ self-pay, and $69.2 \%$ state and local governments. Thus, as expected, both holding insurance and having insurance pay for treatment was relatively uncommon among patients receiving treatment in TEDS-tracked facilities pre-Medicaid expansion.

State-level characteristics are also reported in Table 2. Expanding and non-expanding states were broadly comparable across these characteristics pre-expansion. ${ }^{23}$ We nevertheless control for all of these factors in our regression models.

\subsection{Validity of the research design: TEDS}

Figures 1, 2, and 3 report trends in outcomes for treatment and comparison groups in admissions, insurance status, and payment source. Trends between the two groups of states appear to move in parallel in the pre-period, 2010-2013, for the majority of our outcomes; one exception to this pattern is the self-payment variable where the trend is more ambiguous.

In terms of the post-period we observe a steeper decline in the number of admissions to treatment in non-expanding states than expanding states. In addition, we see larger increases in Medicaid insurance and Medicaid as a source of payment in expanding states in 2015 relative to non-expanding states. There were large declines in the share of patients with uninsured status in

\footnotetext{
${ }^{23}$ We note that our research design, differences-in-differences, requires common trends, not levels, for identification.
} 
both groups of states (but a larger decrease in expansion states) and declines in state and localities as a source of payment for treatment.

Results from regression-based testing of the parallel trends assumption are reported in Tables 3A (admissions), 3B (insurance status), and 3C (payment source). We cannot reject the hypothesis that $\gamma_{1}=0$ in eight of the nine regressions we estimate. The exception to this pattern is the use of states and localities as the source of payment: we find that expanding states experienced a 3.7 percentage point $(7.1 \% ; p<0.05)$ increase in this payment form per year relative to non-expanding states. We return to this issue when interpreting our estimates generated in DD models. Overall, we note that standard error estimates are somewhat large and limit our ability to rule out non-trivial violations of the parallel trends assumption. Reassuringly, the coefficient estimates are small in magnitude in all regressions and, as we report later in the manuscript, our findings are largely insensitive to the inclusion of state-specific time trends.

\subsection{DD regression results: TEDS}

Our core TEDS findings generated in the DD model outlined in Equation (1) are reported in Tables 4A (admissions), 4B (insurance status), and 4C (payment source).

We estimate a modest, but not statistically significant, increase in admissions to specialty SUD treatment after Medicaid expansion. Specifically, we find an annual increase of 83 additional admissions per 100,000 non-elderly adults in expansion states relative to nonexpansion states; a 7.8\% increase over mean in the expansion state sample pre-expansion.

When we look at insurance status among patients in treatment, we find that, following a state expansion, the probability that a patient held Medicaid insurance coverage increased by 13.2 percentage points while the probability that a patient was uninsured declined by 16.6 percentage points (Table 4B). This pattern of results implies that virtually all the individuals in 
treatment gaining Medicaid post expansion were previously uninsured, and, while not definitive, suggests that extensive crowd-out did not occur.

The magnitude of these estimated effects is substantial: they imply a $71 \%$ increase in Medicaid coverage and a $28 \%$ decline in uninsurance relative to the pre-expansion mean for the expansion states. These substantial relative effect sizes are in line with large-scale changes in private insurance coverage documented among young adults with SUDs under the ACA dependent coverage mandate (Saloner, Akosa Antwi et al. 2017). Moreover, our baseline proportion for Medicaid coverage is low (see Table 2) which leads to large relative changes.

Our payment source findings largely mirror the insurance estimates (Table 4C). In particular, we find that following a state Medicaid expansion, patients in expanding states were 12.9 percentage points more likely to have Medicaid as a primary source of payment for treatment - a $75 \%$ increase over the pre-expansion baseline proportion in expanding states. Such patients were also 11.5 percentage points less likely to have states and localities pay for treatment - a $22 \%$ decrease over the pre-expansion baseline proportion in expanding states. The similarity in magnitude (but opposing sign) of the coefficient estimates is in line with the hypothesis that facilities were able to offset treatment that had previously been financed by state and local grant funding with Medicaid payments. As in the insurance results, Medicaid payment was modest in the pre-expansion period (see Table 2), which leads to the large percent increase.

We find in Table $3 \mathrm{C}$ that expanding states experienced an increase in the use of funding from states and localities to pay for specialty SUD treatment in the pre-expansion period relative to non-expanding states. Our DD estimates suggest that expanding states also experienced a decrease in this source of payment post-expansion relative to non-expanding states. Combining 
these two findings suggests that our DD estimates may in fact understate the effects of the Medicaid expansions on the use of states and localities to pay for treatment.

More specifically, we can 'subtract off' the pre-treatment trend in this variable and correct our estimate of the Medicaid effect: $(-0.115-0.037) /-0.115=-0.152$. This corrected estimate suggests that this source of payment declined by $29 \%$. In unreported analyses, we bootstrap standard error for the 'corrected' DD estimate for this payment source and find that this estimate is statistically different from zero at the $1 \%$ level. $^{24}$

\section{Results for prescription medication use in the State Drug Utilization Database}

\subsection{Summary statistics: SDUD}

Table 5 reports summary statistics for the pre-expansion period for expanding states and 2010-2013 for non-expanding states using the SDUD data. The mean quarterly prescription rate for outpatient SUD medications financed by Medicaid per 100,000 adults 18 to 64 years was 806 in expanding states pre-expansion and 421 in the non-expanding states 2011-2013.

\subsection{Validity of the research design: SDUD}

Figure 4 documents similar patterns in prescription outcomes over the 2011 to 2013 period for expanding and non-expanding states, followed by an increase in prescription rates in expanding states relative to non-expanding states 2014 to 2015.

Table 6 reports regression-based parallel trends testing of the SDUD: we estimate Equation (2) in these data. We are most interested in the coefficient estimate on the interaction between the treatment group indicator and the linear time trend $\left(\hat{\gamma}_{1}\right)$. We find that prescription medications used to treat SUDs in outpatient settings increased by 12 prescriptions per 100,000 non-elderly adults each quarter (or 1.4\%) in expansion states relative to non-expansion states.

\footnotetext{
${ }^{24}$ More specifically, we applied a non-parametric bootstrap using 500 repetitions to the difference. More details are available on request from the corresponding author.
} 


\subsection{DD regression results: $S D U D$}

Our DD estimates for the effect of the ACA Medicaid expansions on prescriptions for medications used to treat SUDs in outpatient settings are reported in Table 6. We find that expanding states experienced an increase of 356 prescriptions per 100,000 adults 18 to 64 years per quarter post expansion, relative to non-expanding states. This estimate represents a $44 \%$ increase over the pre-expansion mean in expanding states. ${ }^{25}$ To account for differences in preexpansion trends we identified for expansion and non-expansion states, we subtract our estimate of the pre-treatment trend from the DD estimate and divide that number by the baseline: (35612)/806. This correction implies that, post-expansion, prescriptions for medications used to treat SUDs in outpatient settings increased $43 \%$ in expanding states relative to non-expanding states. We bootstrap this corrected estimate and find that it is statistically significant at the $1 \%$ level. ${ }^{26}$

\section{Extensions and robustness checks}

\subsection{ACA-related Medicaid expansion, and fatal alcohol poisonings and drug-related overdoses}

We have explored the effect of ACA-related Medicaid expansions on SUD treatment use.

Since these expansions are ultimately aimed at improving health, understanding whether they affected key health outcomes is important in assessing the value of Medicaid expansion. To provide some evidence on relevant health outcomes, we next estimate the effect of Medicaid

\footnotetext{
${ }^{25}$ SDUD contains information on the total, Medicaid, and non-Medicaid reimbursement for each prescription. This information allows us to explore whether Medicaid or patients (through cost-sharing) were responsible for financing use of these medications. In unreported analyses we regressed total, Medicaid, and non-Medicaid reimbursements on the expansion indicator using Equation (1). Broadly, total reimbursement increased among expansion states relative to non-expansion states in the post-expansion period, and Medicaid financed the vast majority of the prescriptions (the coefficient estimates in the total and Medicaid reimbursement regressions are very similar in magnitude while the coefficient estimate in the non-Medicaid regression carries a negative sign; we note that this final coefficient estimate is imprecise). This finding is perhaps not surprising as cost-sharing is low in the Medicaid program, but nonetheless the finding implies that Medicaid patients did not bear the full financial burden of increased utilization of medications used to treat SUDs. See Supplementary Table 10.

${ }^{26}$ More specifically, we applied a non-parametric bootstrap using 500 repetitions to the difference. More details are available on request from the corresponding author.
} 
expansions on proxies for harmful substance use within the population: fatal alcohol poisonings and drug-related overdoses.

We examine data from the National Vital Statistics Mortality Files (NVSM) between 2010 and 2015. NVSM tracks all-cause mortality in the U.S. and therefore provides us with the universe of deaths classified as alcohol poisoning and drug-related overdose. We construct the number of fatal alcohol poisonings and drug-related overdoses. ${ }^{27}$ We use data on fatal alcohol poisonings and drug-related overdoses among non-elderly adults: 18 to 64 years. We convert deaths to the rate per 100,000 non-elderly adults per quarter. We use the same procedure to link Medicaid expansion dates to the NVSM data as we do for the SDUD. ${ }^{28}$

We estimate Equation (1) in the NVSM data. Results are reported in Appendix Table 4. We also report regression-based parallel trends testing, which supports the hypothesis that the NVSM data are able to satisfy the parallel trends assumption. Our findings do not suggest that the Medicaid expansions we study led to changes in fatal alcohol poisonings and drug-related overdoses: the regression coefficient estimate, while it carries a negative sign and thus is suggestive of a decline in these deaths, is small relative to the baseline mean and is not statistically different from zero.

\subsection{Policy endogeneity: TEDS and SDUD}

A perennial concern in analyses of health and healthcare policies, such as the Medicaid expansions we investigate here, is that state legislatures concerned with deteriorating health or underutilization of healthcare services within the population may implement policies to address

\footnotetext{
${ }^{27}$ Specifically, we use the public use Underlying Cause of Death files for deaths attributable to alcohol and drugs from the Centers for Disease Control and Prevention. There were no suppressed cells in the data.

${ }^{28}$ We aggregate the NVSM to the quarter level. More details available on request.
} 
these problematic trends. In such a scenario, outcomes may lead to changes in policies rather than policies leading to changes in outcomes (i.e., state-level reverse causality).

To explore this possibility, we estimate an event study (Autor 2003). We estimate a modification of Equation (1) in which we include a series of policy leads and lags in the regression model. We exclude early expanding states from this analysis. In TEDS, our leads and lags consist of interactions between year indicators for 2010-2012 and 2014-2015, and an indicator for expanding states (i.e., those states that expanded by 2015, the final year of our study period). 2013 is the omitted year. Because the SDUD is provided at the quarter level, we estimate a slightly different specification that takes advantage of the finer unit of aggregation (i.e., quarter and not year) in constructing leads/lags and our omitted period is Q4 2013.

If we find evidence that the leads are statistically different from zero, this pattern in the data might suggest that our data is subject to policy endogeneity. However, after we condition for such endogeneity through the inclusion of policy leads, we can minimize concerns regarding reverse causality bias and recover causal estimates for the lags (our primary objects of interest).

Results generated in the event study are reported in Appendix Table 5A (admissions), 5B (insurance status), 5C (payment source), and 5D (medications). We find little evidence of policy endogeneity: the coefficient estimates on the leads are generally statistically indistinguishable from zero and F-tests of lead joint significance lead to the same conclusion. Moreover, across our event study specifications we find evidence expansion effects increased over time.

\subsection{Controlling for between-state differences}

Although we cannot reject the null hypothesis that the treatment and comparison groups trended similarly in the pre-treatment period, the standard errors on the interaction between the treatment group and the linear time trend in Equation (2) are large and prevent us from ruling out 
non-trivial differences in pre-treatment trends for some outcomes. Indeed, we find evidence of different pre-treatment trends for two outcomes (the use of funds from states and localities to pay for treatment and prescription medications) in expanding and non-expanding states.

To explore the extent to which our findings may be driven by differences in pre-treatment trends between the treatment and comparison groups, we re-estimate Equation (1) including state-specific linear time trends. Including these state trends allows each state to follow a separate, albeit linear, trend in the outcome variables and thus allows us to control for trend differences. A concern is that some of our time-varying state controls may themselves be influenced by the Medicaid expansions we study, leading to over-controlling bias (Angrist and Pischke 2009). To explore the extent of any such bias on our regression coefficients, we reestimate Equation (1) excluding time-varying state-level controls.

Results from these analyses are reported in Tables 6A (admissions), 6B (insurance status), 6C (payment source), and 6D (prescriptions). Overall, our findings are broadly robust to the inclusion of state-specific linear time trends. However, as these models are data intensive and we have a relatively small amount of variation in the data (see Table 1), we not surprisingly find that our results are in some specifications less precisely estimated when trends are included. For example, the coefficient estimate in the use of Medicaid to pay for treatment is no longer precise. Reassuringly, the coefficients are quite stable in terms of sign and magnitude (although somewhat smaller in some regressions) vis-à-vis our core findings. We find that the coefficient estimate in the SDUD is substantially smaller when the state trends are included: a $17 \%$ decline in the model with trends vs. a $43 \%$ decline in the model without trends post-expansion. However, the $95 \%$ confidence intervals (available on request) for the coefficient estimates overlap, preventing us from ruling out similar effect sizes across specifications. Additionally, 
the estimated coefficients are not appreciably altered when the time-varying state-level controls are excluded from the regression model.

\subsection{Population weighting}

Our regressions are unweighted. However, there is some controversy within the economics literature as to whether weights should be applied in economic analyses seeking to estimate causal effects (Angrist and Pischke 2009, Solon, Haider et al. 2015). To explore the robustness of our findings, we re-estimate our regressions using population weights (i.e., the state population ages 18 to 64 serve as our weights). Results from these weighted analyses are reported in Appendix Table 7A (admissions), 7B (insurance status), 7C (payment source), and 7D (prescription medications).

Our findings are broadly robust to weighting. However, we also find that holding private insurance and using private insurance to pay for treatment increased in expanding states relative to non-expanding states in the post-expansion period. We are uncertain why more individuals in expansion states would also use private insurance after expansion - one potential explanation is that Medicaid expansion could induce greater acceptance of insurance overall, leading to a positive spillover on privately insured individuals (Glied and Zivin 2002, Finkelstein 2007). ${ }^{29}$

\subsection{Referral source}

A common referral source to SUD treatment is the criminal justice system. Indeed, over one third of the admissions in our TEDS analysis data set are referred through this system. As noted earlier in the manuscript, legally coerced admissions may be less responsive to changes in price attributable to a public insurance expansion than other admissions. We next exclude all admissions referred through the criminal justice system and re-estimate our analysis of the TEDS

\footnotetext{
${ }^{29}$ The coefficient estimates, while imprecise, in the unweighted regressions also carried a positive sign.
} 
(we are not able to make such an exclusion in the SDUD). Results - reported in Appendix Tables 8A (admissions), 8B (insurance), and 8C (payment) - are not appreciably different from results reported in the manuscript.

\subsection{Additional extensions and robustness checks}

We explore whether there are changes in the composition of patients receiving treatment in TEDS-tracked facilities. Compositional changes are important to test because, among other things, they can provide some indication of either changes in provider behavior, e.g., differential acceptance of specific populations (Sloan, Mitchell et al. 1978), or choices patients may make regarding where to seek treatment. ${ }^{30}$

We construct indicator variables for sex (male vs. female), age (18 to 34 years vs. 35 years and older), race/ethnicity (white, African American, other race, and Hispanic), primary substance targeted for treatment (alcohol vs. drugs; we also separately consider opioids: heroin, non-prescription methadone, oxycodone, and other opioids and synthetics), prior treatment (no prior treatment vs. any prior treatment), and referral source (criminal justice system vs. all other referral sources). We find some evidence that post-expansion patients admitted to treatment programs in expansion states are relatively less likely to be white and less likely to be in treatment for their first time, relative to the trend in non-expansion states. ${ }^{31}$

Patients gaining access to Medicaid may be able access specialty treatment in settings that may not have been available when they were uninsured. To explore this issue, we estimated a series of regressions in which we model specialty SUD treatment setting - detoxification, nonintensive outpatient, intensive outpatient, and inpatient - on Medicaid expansions in Equation (1)

\footnotetext{
${ }^{30}$ Our data will not allow us to shed light on whether this phenomenon is driven by providers or patients, however.

${ }^{31}$ See Supplementary Tables $11 \mathrm{~A}$ and $11 \mathrm{~B}$.
} 
using TEDS. We find no evidence that these expansions altered the setting in which patients receive care. ${ }^{32}$

Finally, we have estimated the TEDS specialty admission rate and SDUD prescription medication rate regressions in the insurance and payment state samples. Results are analogous to our main admissions findings (Table 4A), although the specialty treatment admission rate coefficient estimated in the payment sample of states is precise. ${ }^{33}$

\section{Discussion}

In this study we investigated the effects of recent state-level Medicaid expansions that occurred under the 2010 Affordable Care Act on substance use disorder (SUD) treatment utilization. By 2017, 32 states (including DC) expanded income eligibility for Medicaid up to $138 \%$ of the federal poverty level, with the majority of states expanding in January 2014 . These expansions targeted populations that previously had little access to insurance in the United States: low-income, non-elderly childless adults. Moreover, a generous set of SUD services was a required benefit under these expansions (Beronio, Glied et al. 2014). These services may hold particular value for the group of individuals that gained insurance coverage through these expansions as such individuals have elevated SUD prevalence (Busch, Meara et al. 2013).

Although we estimate a moderate size increase in admissions to specialty SUD treatment after states expanded Medicaid, the coefficient was not statistically significant. Larger changes in use of these SUD services may also take time because of existing capacity constraints within the specialty SUD treatment delivery system (Carr, Xu et al. 2008, Buck 2011): meaning that providers may initially lack the space to allow additional patients into treatment (Saloner 2017).

\footnotetext{
${ }^{32}$ See Supplementary Table 12.

${ }^{33}$ See Supplementary Tables $13 \mathrm{~A}$ and $13 \mathrm{~B}$.
} 
We find that the ACA-related Medicaid expansions substantially changed the insurance status of treated populations and the financial burden of treatment. Specifically, Medicaid as a source of insurance increased 13.2 percentage points or $71 \%$ (offset mainly by a reduction in the uninsured) and Medicaid as a source of payment increased 12.9 percentage points or $75 \%$ (offset mainly by reduced spending by states and localities which captures charity care). The reduced spending by states and localities on safety net treatment can also increase resources available within constrained public health budgets to address other public health priorities. For patients, increasing payment by Medicaid can also reduce out-of-pocket spending burden - i.e., a potential financial relief. Recent research on the ACA Medicaid expansion finds that expansions improved financial wellbeing and reduced debt in expansion states (Hu, Kaestner et al. 2016, Sojourner and Golberstein 2017), which is in line with our finding for payment source.

Our TEDS findings can also be compared to other recent studies that have examined how the coverage and sources of payment changed after Medicaid expansion in other low-income and safety net settings. Among individuals 19-64 with family incomes less than $138 \%$ of the federal poverty level, post-expansion Medicaid insurance increased by 10.2 percentage points (34\%) while uninsurance declined by 7.4 percentage points $(22 \%)$ in expanding states relative to nonexpanding states (Wherry and Miller 2016). The share of Medicaid insured patients treated at community health centers increased by 11.8 percentage points (30\%) in 2014 in expansion states compared to non-expansion states (Cole, Galárraga et al. 2017). Moreover, inpatient hospital discharges covered by Medicaid increased by 6.2 percentage points (18\%) in expansion states (Nikpay, Buchmueller et al. 2016). While our estimated absolute effect sizes (i.e., percentage points) are broadly in line with previous studies examining insurance and use of other healthcare services, our estimated relative effect sizes (i.e., percent) are larger in magnitude. We suspect 
that the larger magnitude of our estimated relative effects is due to the comparatively modest role Medicaid played in the financing of specialty SUD treatment pre-expansion vs. other healthcare settings. In expansion states just $19 \%$ of patients admitted to specialty SUD treatment held Medicaid and 17\% used Medicaid to pay for treatment in the pre-expansion period (2010-2013).

We find that the volume of prescriptions for medications approved by the Food and Drug Administration to treat SUDs in outpatient settings reimbursed by Medicaid increased by $43 \%$ in expanding states after the expansion relative to non-expanding states.

The fact that our study find such large increases in Medicaid-reimbursed prescription drugs could suggest that individuals enrolling under ACA provisions were better able to (or more willing to) access treatment through a private physician's office than through specialty treatment setting. Moreover, these findings suggest that newly enrolled with SUD are able to form relationships with healthcare providers as the medications that we study require a prescription from a provider in order to be filled.

Our study is not without limitations. First, because most of the Medicaid expansions occurred between 2014 and 2016, we are relying on only two years of post-expansion data for all but the early expanding states. This feature is not unique to our study and instead is a limitation to all current studies of which we are aware examining Medicaid expansion effects. Second, our insurance and payment analysis of TEDS relies on just over half the states. Third, while we study two important forms of SUD treatment (specialty treatment and prescription medications obtained in outpatient settings), we do not capture all dimensions of SUD treatment. Fourth, the SDUD allows us to study just one payer (i.e., Medicaid).

Additionally our study, like many other investigations into the effects of ACA-related Medicaid expansions, does not address other ACA-related changes that may have driven 
enrollment increases. For example, Frean, Gruber et al. (2017) find that 'woodwork effects' (previously eligible individuals taking up Medicaid) may have increased Medicaid enrollment due to greater outreach efforts. Another change occurring under the ACA in all states (not just expansion states) was a switch to the Modified Adjusted Gross Income (MAGI) criteria, which may have resulted in more individuals becoming eligible for coverage under pre-ACA eligibility categories. If these, or other, changes differentially affected Medicaid enrollment across expansion and non-expansion states, then our estimates will conflate these effects.

Our findings are both timely and important. While the Trump Administration and many members of Congress have expressed concern about capacity to treat individuals with SUD amidst the opioid epidemic, ${ }^{34}$ there have also been serious efforts to repeal core provisions of the ACA including the Medicaid expansions we study. Proposed repeals of Medicaid expansion would increase the uninsured rate (Congressional Budget Office 2017b, Congressional Budget Office 2017a) and individuals with SUDs would be particularly hard hit (Frank and Glied 2017). Our findings suggest that curtailing Medicaid coverage would impede access to SUD treatment in specialty settings and in physician offices. Policymakers considering the effects of repealing or restructuring Medicaid should consider the effects on availability of low-cost SUD treatment. Our findings also speak to the relevance of Medicaid in state and local budgets-especially since SUD services are a major expenditure for states and localities. Further evaluation can indicate whether expanded Medicaid coverage and funding had positive impacts on the health of populations in SUD treatment, and on the communities in which they reside.

\footnotetext{
${ }^{34}$ See for example: http://www.pbs.org/newshour/rundown/heres-trumps-new-executive-order-means-opioidaddiction/ and https://www.capito.senate.gov/news/press-releases/capito-welcomes-recommendations-ofadministrations-drug-abuse-commission- (accessed August $\left.3^{\text {rd }}, 2017\right)$.
} 
Table 1. State Affordable Care Act (2010) related Medicaid expansions: 2010-2017

\begin{tabular}{|c|c|}
\hline State & Expansion date \\
\hline \multicolumn{2}{|l|}{ Early expanding states } \\
\hline California & $7 / 1 / 2011$ \\
\hline Connecticut & $4 / 1 / 2010$ \\
\hline District of Columbia & $7 / 1 / 2010$ \\
\hline Minnesota & $3 / 1 / 2011$ \\
\hline New Jersey & $4 / 14 / 2011$ \\
\hline Washington & $1 / 3 / 2011$ \\
\hline \multicolumn{2}{|c|}{ States expanding in 2014} \\
\hline Arizona & $1 / 1 / 2014$ \\
\hline Arkansas & $1 / 1 / 2014$ \\
\hline Colorado & $1 / 1 / 2014$ \\
\hline Delaware & $1 / 1 / 2014$ \\
\hline Hawaii & $1 / 1 / 2014$ \\
\hline Illinois & $1 / 1 / 2014$ \\
\hline Iowa & $1 / 1 / 2014$ \\
\hline Kentucky & $1 / 1 / 2014$ \\
\hline Maryland & $1 / 1 / 2014$ \\
\hline Massachusetts & $1 / 1 / 2014$ \\
\hline Michigan & $4 / 1 / 2014$ \\
\hline Nevada & $1 / 1 / 2014$ \\
\hline New Hampshire & $8 / 15 / 2014$ \\
\hline New Mexico & $1 / 1 / 2014$ \\
\hline New York & $1 / 1 / 2014$ \\
\hline North Dakota & $1 / 1 / 2014$ \\
\hline Ohio & $1 / 1 / 2014$ \\
\hline Oregon & $1 / 1 / 2014$ \\
\hline Rhode Island & $1 / 1 / 2014$ \\
\hline Vermont & $1 / 1 / 2014$ \\
\hline West Virginia & $1 / 1 / 2014$ \\
\hline \multicolumn{2}{|l|}{ Late expanding states } \\
\hline Alaska & $9 / 1 / 2015$ \\
\hline Indiana & $2 / 1 / 2015$ \\
\hline Montana & $1 / 1 / 2016$ \\
\hline Louisiana & $7 / 1 / 2016$ \\
\hline Pennsylvania & $1 / 1 / 2015$ \\
\hline
\end{tabular}

Notes: Medicaid expansion dates derived from Kaiser Family Foundation and Sommers et al (2013). 
Table 2. Summary statistics for expansion and non-expansion states: TEDS 2010-2013

\begin{tabular}{|c|c|c|}
\hline Sample: & Expansion states & Non-expansion states \\
\hline \multicolumn{3}{|l|}{ Admissions } \\
\hline Admissions per 100,000 non-elderly adults & 1062 & 841 \\
\hline \multicolumn{3}{|l|}{$\begin{array}{l}\text { Insurance status }(N=68 \text { in expansion states, } N=44 \text { in } \\
\text { non-expansion states)* }\end{array}$} \\
\hline Private insurance & 0.114 & 0.063 \\
\hline Medicaid insurance & 0.186 & 0.157 \\
\hline Other insurance & 0.109 & 0.077 \\
\hline Uninsured & 0.591 & 0.703 \\
\hline \multicolumn{3}{|l|}{$\begin{array}{l}\text { Payment source }(N=55 \text { in expansion states, } N=39 \text { in } \\
\text { non-expansion states })^{* *}\end{array}$} \\
\hline Private insurance & 0.087 & 0.036 \\
\hline Medicaid insurance & 0.173 & 0.083 \\
\hline Self-pay & 0.218 & 0.189 \\
\hline State and local government & 0.521 & 0.692 \\
\hline \multicolumn{3}{|l|}{ State characteristics } \\
\hline Age & 38.20 & 37.47 \\
\hline Female & 0.506 & 0.507 \\
\hline Male & 0.494 & 0.493 \\
\hline White & 0.395 & 0.400 \\
\hline African American & 0.194 & 0.195 \\
\hline Other race & 0.448 & 0.441 \\
\hline Hispanic & 0.113 & 0.090 \\
\hline Foreign born & 0.709 & 0.723 \\
\hline Less high school & 0.080 & 0.130 \\
\hline High school & 0.098 & 0.057 \\
\hline Some college & 0.107 & 0.075 \\
\hline College degree & 0.310 & 0.327 \\
\hline Married & 0.297 & 0.295 \\
\hline Divorced/separated/widowed & 0.191 & 0.195 \\
\hline Never married & 0.202 & 0.183 \\
\hline Urban & 0.650 & 0.561 \\
\hline Rural & 0.350 & 0.439 \\
\hline Disabled & 0.131 & 0.136 \\
\hline Family income $(\$)$ & 78429 & 70646 \\
\hline Unemployment rate & 7.880 & 7.357 \\
\hline Poverty rate & 13.77 & 14.80 \\
\hline Maximum monthly SNAP benefit for a family of $4(\$)$ & 726.7 & 705.4 \\
\hline Maximum monthly TANF benefit for a family of $4(\$)$ & 608.0 & 429.4 \\
\hline Democrat governor & 0.544 & 0.205 \\
\hline Prescription drug monitoring program & 0.845 & 0.807 \\
\hline Population & 3539540 & 3724064 \\
\hline
\end{tabular}

Notes: Data are aggregated to the state-year level. The pre-treatment period for early adopting states includes the years between 2010 and the expanding year.

*States contributing data on insurance status includes the following states: AK, AL, AR, CO, DC, DE, HI, IA, IL, IN, KS, KY, MA, MD, ME, MO, MT, ND, NE, NH, NJ, NV, OR, PA, SC, SD, TN, TX, and UT.

**States contributing sample on payment includes the following states: AK, AR, CO, DC, HI, IA, ID, KS, KY, MO, MS, MT, ND, NE, NH, NJ, NV, OH, PA, RI, SC, SD, TX, UT, and VT. 
Table 3A. Parallel trends testing for admissions per 100,000 non-elderly adults: TEDS 2010-2013

\begin{tabular}{lc}
\hline \hline Outcome: & Admissions \\
\hline Pre-expansion mean in the expansion state group & 1062 \\
\hline Treat*time & -8.935 \\
& $(23.105)$ \\
\hline $\mathrm{N}$ & 179 \\
\hline
\end{tabular}

Notes: All models estimated with OLS and control for state demographics, state fixed effects, and year fixed effects. Standard errors are clustered at the state level and are reported in parentheses. Early expanding states excluded from the sample.

$* * * ; * ; *=$ statistically different from zero at the $1 \% ; 5 \% ; 10 \%$ level.

Table 3B. Parallel trends testing for insurance status: TEDS 2010-2013

\begin{tabular}{lcccc}
\hline \hline Outcome: & Private & Medicaid & Other insurance & Uninsured \\
\hline $\begin{array}{l}\text { Pre-expansion proportion in } \\
\text { the expansion state group }\end{array}$ & 0.114 & 0.186 & 0.109 & 0.591 \\
\hline Treat*time & & & & \\
& 0.001 & 0.004 & 0.001 & -0.006 \\
$\mathrm{~N}$ & $(0.005)$ & $(0.008)$ & $(0.007)$ & $(0.011)$ \\
\hline
\end{tabular}

Notes: All models estimated with OLS and control for state demographics, state fixed effects, and year fixed effects. Insurance state sample includes the following states: $\mathrm{AK}, \mathrm{AL}, \mathrm{AR}, \mathrm{CO}, \mathrm{DC}, \mathrm{DE}, \mathrm{HI}, \mathrm{IA}, \mathrm{IL}, \mathrm{IN}, \mathrm{KS}, \mathrm{KY}, \mathrm{MA}, \mathrm{MD}$, ME, MO, MT, ND, NE, NH, NJ, NV, OR, PA, SC, SD, TN, TX, and UT. Standard errors are clustered at the state level and are reported in parentheses. Early expanding states excluded from the sample.

$* * * ; * ; *=$ statistically different from zero at the $1 \% ; 5 \% ; 10 \%$ level.

Table 3C. Parallel trends testing for payment source: TEDS 2010-2013

\begin{tabular}{lcccc}
\hline \hline Outcome: & Private & Medicaid & Self-pay & $\begin{array}{c}\text { States and } \\
\text { localities }\end{array}$ \\
\hline $\begin{array}{l}\text { Pre-expansion proportion in } \\
\text { the expansion state group }\end{array}$ & 0.087 & 0.173 & 0.109 & 0.521 \\
\hline Treat*time & & & -0.024 & $0.037^{* *}$ \\
& -0.003 & -0.010 & $(0.016)$ & $(0.017)$ \\
\hline $\mathrm{N}$ & $(0.005)$ & $(0.007)$ & 91 & 91
\end{tabular}

Notes: All models estimated with OLS and control for state demographics, state fixed effects, and year fixed effects. Payment source state sample includes the following states: AK, AR, CO, DC, HI, IA, ID, KS, KY, MO, MS, MT, ND, NE, NH, NJ, NV, OH, PA, RI, SC, SD, TX, UT, and VT. Standard errors are clustered at the state level and are reported in parentheses. Early expanding states excluded from the sample.

$* * * ; * ; *=$ statistically different from zero at the $1 \% ; 5 \% ; 10 \%$ level. 
Table 4A. Effect of ACA Medicaid expansions on admissions per 100,000 non-elderly adults: TEDS 20102015

\begin{tabular}{lc}
\hline \hline Outcome: & Admissions \\
\hline Pre-expansion mean in the expansion state group & 1062 \\
\hline DD & 83.454 \\
& $(54.081)$ \\
\hline $\mathrm{N}$ & 299 \\
\hline
\end{tabular}

Notes: All models estimated with OLS and control for state demographics, state fixed effects, and year fixed effects. Standard errors are clustered at the state level and are reported in parentheses.

$* * * ; * ; *=$ statistically different from zero at the $1 \% ; 5 \% ; 10 \%$ level.

Table 4B. Effect of ACA Medicaid expansions on insurance status: TEDS 2010-2015

\begin{tabular}{lcccc}
\hline \hline Outcome: & Private & Medicaid & Other insurance & Uninsured \\
\hline $\begin{array}{l}\text { Pre-expansion proportion in } \\
\text { the expansion state group }\end{array}$ & 0.114 & 0.186 & 0.109 & 0.591 \\
\hline DD & & & & \\
& 0.026 & $0.132^{* *}$ & 0.009 & $-0.166^{* * *}$ \\
\hline $\mathrm{N}$ & $(0.016)$ & $(0.048)$ & $(0.013)$ & $(0.034)$ \\
\hline
\end{tabular}

Notes: All models estimated with OLS and control for state demographics, state fixed effects, and year fixed effects. Insurance state sample includes the following states: $\mathrm{AK}, \mathrm{AL}, \mathrm{AR}, \mathrm{CO}, \mathrm{DC}, \mathrm{DE}, \mathrm{HI}, \mathrm{IA}, \mathrm{IL}, \mathrm{IN}, \mathrm{KS}, \mathrm{KY}, \mathrm{MA}, \mathrm{MD}$, ME, MO, MT, ND, NE, NH, NJ, NV, OR, PA, SC, SD, TN, TX, and UT. Standard errors are clustered at the state level and are reported in parentheses.

$* * * ; * ; *=$ statistically different from zero at the $1 \% ; 5 \% ; 10 \%$ level.

Table 4C. Effect of ACA Medicaid expansions on payment source: TEDS 2010-2015

\begin{tabular}{|c|c|c|c|c|}
\hline Outcome: & Private & Medicaid & Self-pay & $\begin{array}{l}\text { States and } \\
\text { localities }\end{array}$ \\
\hline $\begin{array}{l}\text { Pre-expansion proportion in } \\
\text { the expansion state group }\end{array}$ & 0.087 & 0.173 & 0.109 & 0.521 \\
\hline DD & $\begin{array}{c}0.015 \\
(0.012)\end{array}$ & $\begin{array}{c}0.129 * * * \\
(0.036)\end{array}$ & $\begin{array}{l}-0.029 \\
(0.025)\end{array}$ & $\begin{array}{c}-0.115 * * \\
(0.045)\end{array}$ \\
\hline $\mathrm{N}$ & 145 & 145 & 145 & 145 \\
\hline
\end{tabular}

Notes: All models estimated with OLS and control for state demographics, state fixed effects, and year fixed effects. Payment source state sample includes the following states: AK, AR, CO, DC, HI, IA, ID, KS, KY, MO, MS, MT, ND, NE, NH, NJ, NV, OH, PA, RI, SC, SD, TX, UT, and VT. Standard errors are clustered at the state level and are reported in parentheses.

$* * * ; * * ; *=$ statistically different from zero at the $1 \% ; 5 \% ; 10 \%$ level. 
Table 5. Summary statistics for expansion and non-expansion states in the pre-expansion period: SDUD 2011-2013

\begin{tabular}{lcc}
\hline \hline Sample: & Expansion states & Non-expansion states \\
\hline Prescription medications financed by Medicaid & & \\
\hline Prescriptions per 100,000 non-elderly adults & 806 & 421 \\
\hline State characteristics & & 37.56 \\
\hline Age & 38.31 & 0.507 \\
Female & 0.506 & 0.493 \\
Male & 0.494 & 0.719 \\
White & 0.717 & 0.133 \\
African American & 0.081 & 0.058 \\
Other race & 0.091 & 0.090 \\
Hispanic & 0.111 & 0.075 \\
Foreign born & 0.103 & 0.324 \\
Less high school & 0.307 & 0.295 \\
High school & 0.299 & 0.196 \\
Some college & 0.191 & 0.184 \\
College degree & 0.203 & 0.399 \\
Married & 0.393 & 0.196 \\
Divorced/separated/widowed & 0.195 & 0.442 \\
Never married & 0.449 & 0.564 \\
Urban & 0.648 & 0.436 \\
Rural & 0.352 & 0.137 \\
Disabled & 0.134 & 70618 \\
Family income (\$) & 78037 & 7.033 \\
Unemployment rate & 7.503 & 14.85 \\
Poverty rate & 13.85 & 698.9 \\
Maximum monthly SNAP benefit for a family of 4 (\$) & 714.6 & 422.8 \\
Maximum monthly TANF benefit for a family of 4 (\$) & 596.6 & 0.127 \\
Democrat governor & 0.514 & 0.873 \\
Prescription drug monitoring program & 0.892 & 3717094 \\
Population & 3356365 & 252 \\
\hline N & 296 & \\
Notes: Data are agreg & \\
\hline
\end{tabular}

Notes: Data are aggregated to the state-quarter level. The pre-treatment period for early adopting states includes the years between 2011 and the expanding year.

Table 6. Effect of ACA Medicaid expansions on prescription medications financed by Medicaid per 100,000 non-elderly adults: SDUD 2011-2015

\begin{tabular}{lcc}
\hline \hline Coefficient estimate: & Parallel trends & \\
(Treat*time+) & DD \\
\hline Pre-expansion mean in the expansion state group & 806 & 806 \\
\hline $\mathrm{DD}$ & $11.667^{* *}$ & $355.984^{* * *}$ \\
& $(5.135)$ & $(109.328)$ \\
\hline $\mathrm{N}$ & 536 & 1016 \\
\hline
\end{tabular}

Notes: All models estimated with OLS and control for state demographics, state fixed effects, and period fixed effects. Standard errors are clustered at the state level and are reported in parentheses.

+ Early expanding states dropped from the analysis sample.

$* * * ; * * ; *=$ statistically different from zero at the $1 \% ; 5 \% ; 10 \%$ level. 
Figure 1. Trends in admissions per 100,000 non-elderly adults: TEDS 2010-2015

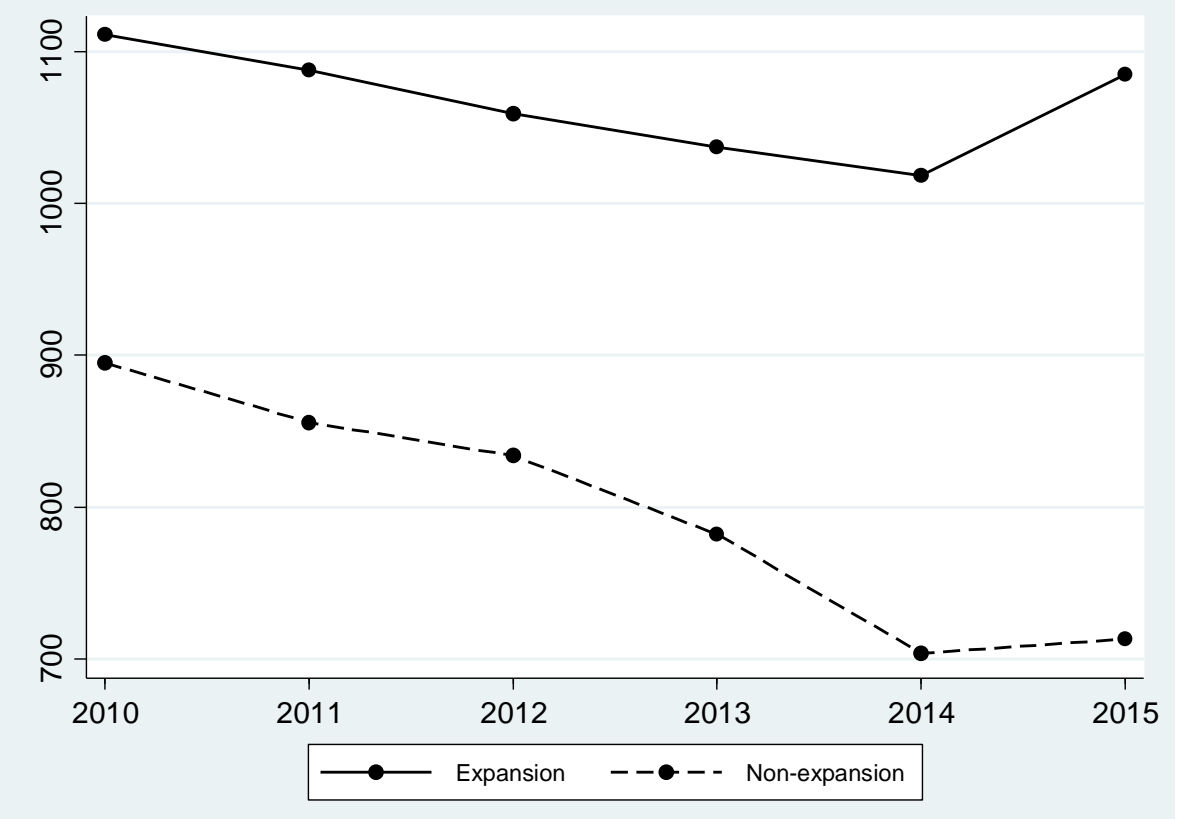

Notes: Early expanding states excluded from the sample.

Figure 2. Trends in insurance status: TEDS 2010-2015
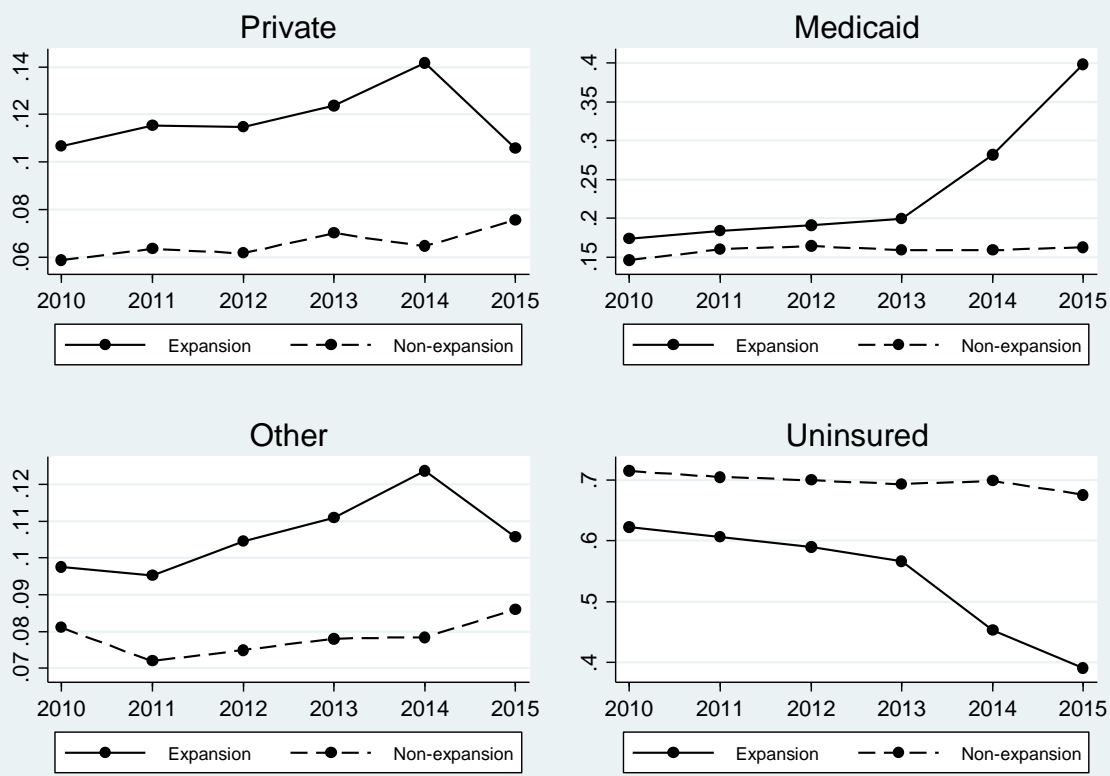

Notes: Outcomes include: private, Medicaid, other insurance, and no insurance. Insurance state sample includes the following states: AK, AL, AR, CO, DC, DE, HI, IA, IL, IN, KS, KY, MA, MD, ME, MO, MT, ND, NE, NH, NJ, NV, OR, PA, SC, SD, TN, TX, and UT. Early expanding states excluded from the sample. 
Figure 3. Trends in payment source: TEDS 2010-2015
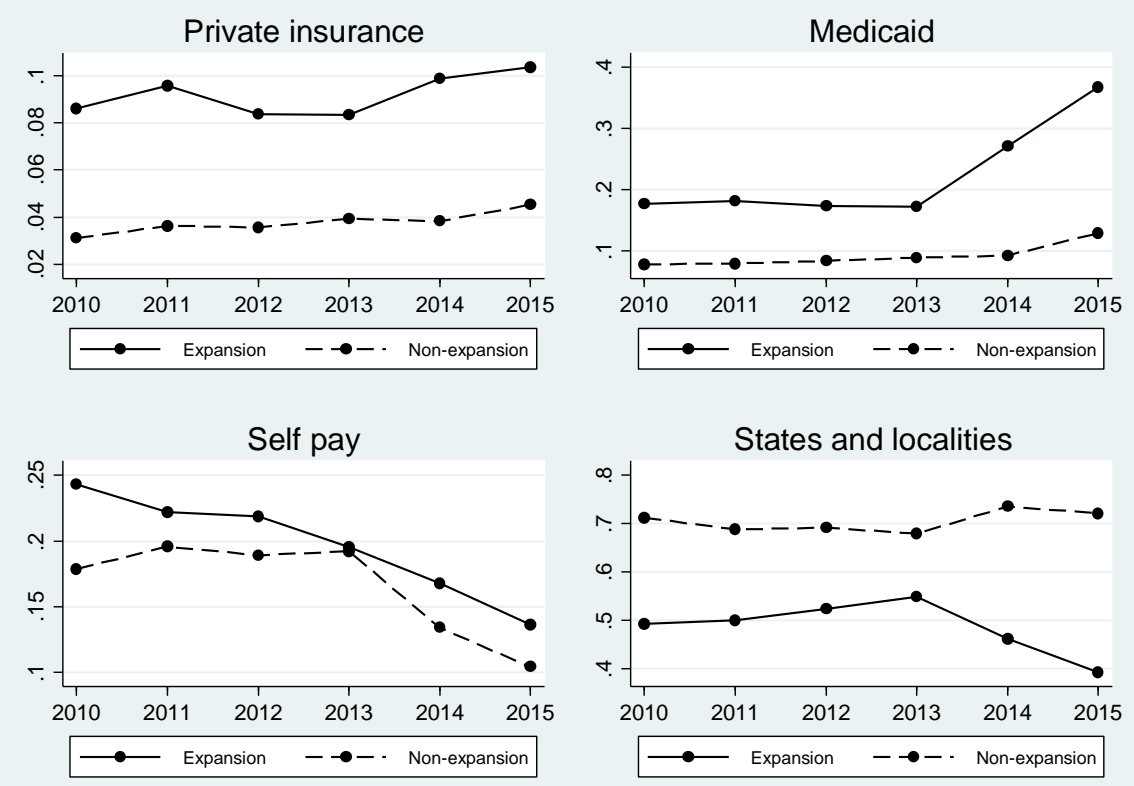

Notes: Outcomes include: private, Medicaid, self-pay, and states and localities. Payment source state sample includes the following states: AK, AR, CO, DC, HI, IA, ID, KS, KY, MO, MS, MT, ND, NE, NH, NJ, NV, OH, PA, RI, SC, SD, TX, UT, and VT. Early expanding states excluded from the sample.

Figure 4. Trends in prescription medications financed by Medicaid per 100,000 non-elderly adults: SDUD 2011-2015

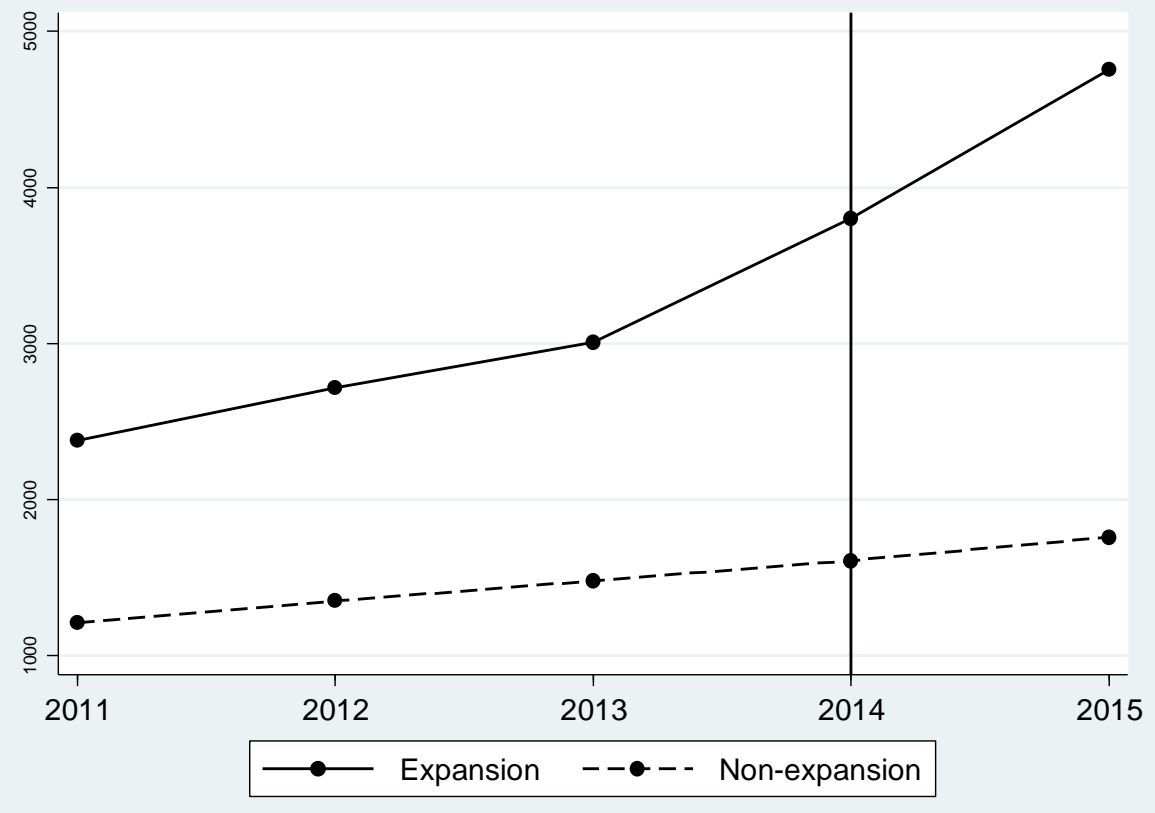

Notes: Early expanding states excluded from the sample. 
Appendix Table 1. States missing from TEDS by year 2010-2015

\begin{tabular}{ll}
\hline \hline Year & States \\
\hline 2010 & MS \\
2011 & -- \\
2012 & -- \\
2013 & -- \\
2014 & SC \\
2015 & GA, KS, OR, PA, and SC \\
\hline
\end{tabular}

Appendix Table 2. TEDS states by sample

\begin{tabular}{ll}
\hline \hline Sample & States \\
\hline Insurance sample: $\mathrm{N}=29$ & $\mathrm{AK}, \mathrm{AL}, \mathrm{AR}, \mathrm{CO}, \mathrm{DC}, \mathrm{DE}, \mathrm{HI}, \mathrm{IA}, \mathrm{IL}, \mathrm{IN}, \mathrm{KS}, \mathrm{KY}, \mathrm{MA}, \mathrm{MD}, \mathrm{ME}, \mathrm{MO}$, \\
& $\mathrm{MT}, \mathrm{ND}, \mathrm{NE}, \mathrm{NH}, \mathrm{NJ}, \mathrm{NV}, \mathrm{OR}, \mathrm{PA}, \mathrm{SC}, \mathrm{SD}, \mathrm{TN}, \mathrm{TX}$, and UT \\
Payment sample: N=25 & $\mathrm{AK}, \mathrm{AR}, \mathrm{CO}, \mathrm{DC}, \mathrm{HI}, \mathrm{IA}, \mathrm{ID}, \mathrm{KS}, \mathrm{KY}, \mathrm{MO}, \mathrm{MS}, \mathrm{MT}, \mathrm{ND}, \mathrm{NE}, \mathrm{NH}, \mathrm{NJ}, \mathrm{NV}$, \\
& $\mathrm{OH}, \mathrm{PA}, \mathrm{RI}, \mathrm{SC}, \mathrm{SD}, \mathrm{TX}, \mathrm{UT}$, and VT \\
\hline
\end{tabular}

Notes: All states appear in the admissions sample.

Appendix Table 3. TEDS sample characteristics by sample

\begin{tabular}{|c|c|c|c|}
\hline Sample: & $\begin{array}{c}\text { Admissions } \\
\text { sample }\end{array}$ & $\begin{array}{c}\text { Insurance } \\
\text { sample }\end{array}$ & $\begin{array}{c}\text { Payment } \\
\text { sample }\end{array}$ \\
\hline Age & 38.03 & 37.89 & 37.74 \\
\hline Female & 0.507 & 0.506 & 0.504 \\
\hline Male & 0.493 & 0.494 & 0.496 \\
\hline Hispanic & 0.393 & 0.394 & 0.395 \\
\hline White & 0.194 & 0.192 & 0.190 \\
\hline African American & 0.451 & 0.452 & 0.453 \\
\hline Other race & 0.111 & 0.097 & 0.097 \\
\hline Foreign born & 0.698 & 0.707 & 0.718 \\
\hline Less high school & 0.107 & 0.105 & 0.091 \\
\hline High school & 0.083 & 0.0911 & 0.094 \\
\hline Some college & 0.103 & 0.098 & 0.092 \\
\hline College degree & 0.311 & 0.308 & 0.309 \\
\hline Married & 0.292 & 0.291 & 0.290 \\
\hline Divorced/separated/widowed & 0.192 & 0.191 & 0.194 \\
\hline Never married & 0.205 & 0.210 & 0.206 \\
\hline Urban & 0.642 & 0.637 & 0.581 \\
\hline Rural & 0.358 & 0.363 & 0.419 \\
\hline Disabled & 0.133 & 0.131 & 0.131 \\
\hline Family income $(\$)$ & 78037 & 79557 & 77921 \\
\hline Unemployment rate & 6.999 & 6.759 & 6.600 \\
\hline Poverty rate & 13.93 & 13.36 & 13.45 \\
\hline Maximum monthly SNAP benefit for a family of $4(\$)$ & 694.9 & 702.5 & 704.9 \\
\hline Maximum monthly TANF benefit for a family of $4(\$)$ & 533.2 & 536.5 & 542.2 \\
\hline Democratic governor & 0.428 & 0.450 & 0.386 \\
\hline Prescription drug monitoring program & 0.866 & 0.811 & 0.821 \\
\hline Population & 3877968 & 3025529 & 2697994 \\
\hline $\mathrm{N}$ & 299 & 169 & 145 \\
\hline
\end{tabular}

Notes: Data are aggregated to the state-year level. Insurance state sample includes the following states: AK, AL, AR, CO, DC, DE, HI, IA, IL, IN, KS, KY, MA, MD, ME, MO, MT, ND, NE, NH, NJ, NV, OR, PA, SC, SD, TN, TX, and UT. Payment source state sample includes the following states: AK, AR, CO, DC, HI, IA, ID, KS, KY, MO, MS, MT, ND, NE, NH, NJ, NV, OH, PA, RI, SC, SD, TX, UT, and VT. 
Appendix Table 4. Effect of ACA Medicaid expansions on alcohol poisoning and drug-related overdose deaths per 100,000 non-elderly adults: NVSM 2010-2015

\begin{tabular}{lcc}
\hline Coefficient estimate: & $\begin{array}{c}\text { Parallel trends } \\
\text { (treat*time+) }\end{array}$ & DD \\
\hline Pre-expansion mean in the expansion state group & 84 & 84 \\
\hline DD & 0.037 & -0.235 \\
& $(0.058)$ & $(0.518)$ \\
\hline $\mathrm{N}$ & 720 & 1224 \\
\hline
\end{tabular}

Notes: All models estimated with OLS and control for state demographics, state fixed effects, and period fixed effects. Standard errors are clustered at the state level and are reported in parentheses.

+ Early expanding states dropped from the analysis sample.

$* * * ; * * *=$ statistically different from zero at the $1 \% ; 5 \% ; 10 \%$ level. 
Appendix Table 5A. Event study for admissions per 100,000 non-elderly adults: TEDS 2010-2015

\begin{tabular}{|c|c|}
\hline Outcome: & Admissions \\
\hline Pre-expansion mean in the expansion state group & 1062 \\
\hline \multirow[t]{2}{*}{$2010 *$ treat } & -7.429 \\
\hline & $(73.793)$ \\
\hline \multirow[t]{2}{*}{$2011 *$ treat } & -10.706 \\
\hline & $(58.941)$ \\
\hline \multirow[t]{2}{*}{$2012 *$ treat } & -26.256 \\
\hline & $(31.902)$ \\
\hline \multirow[t]{2}{*}{$2014 *$ treat } & 55.039 \\
\hline & $(51.539)$ \\
\hline \multirow[t]{2}{*}{$2015 *$ treat } & 114.827 \\
\hline & $(72.923)$ \\
\hline$F$-test of joint significance of policy leads ( $p$-value) & 0.8578 \\
\hline $\mathrm{N}$ & 263 \\
\hline
\end{tabular}

Notes: All models estimated with OLS and control for state demographics, state fixed effects, and year fixed effects. Standard errors are clustered at the state level and are reported in parentheses. The omitted year is 2013. Early expanding states excluded from the sample.

$* * * ; * ; *=$ statistically different from zero at the $1 \% ; 5 \% ; 10 \%$ level.

Appendix Table 5B. Event study for insurance status: TEDS 2010-2015

\begin{tabular}{lcccc}
\hline Outcome: & Private & Medicaid & Other insurance & Uninsured \\
\hline $\begin{array}{l}\text { Pre-expansion proportion in } \\
\text { the expansion state group }\end{array}$ & 0.114 & 0.186 & 0.109 & 0.591 \\
\hline $2010 *$ treat & -0.011 & -0.032 & -0.002 & 0.045 \\
& $(0.014)$ & $(0.038)$ & $(0.020)$ & $(0.035)$ \\
$2011 *$ treat & -0.008 & -0.031 & -0.004 & 0.043 \\
& $(0.014)$ & $(0.031)$ & $(0.021)$ & $(0.027)$ \\
$2012 *$ treat & 0.001 & -0.015 & -0.006 & 0.019 \\
& $(0.013)$ & $(0.017)$ & $(0.013)$ & $(0.021)$ \\
$2014 *$ treat & 0.023 & 0.076 & 0.018 & $-0.117 * *$ \\
& $(0.018)$ & $(0.048)$ & $(0.012)$ & $(0.037)$ \\
$2014 *$ treat & -0.017 & $0.165 * *$ & 0.032 & $-0.180 * * *$ \\
& $(0.026)$ & $(0.065)$ & $(0.024)$ & $(0.054)$ \\
\hline F-test of joint significance & 0.6515 & 0.7124 & 0.9154 & 0.4803 \\
of policy leads $(p$-value) & & & & 157 \\
\hline $\mathrm{N}$ & 157 & 157 & & 157 \\
\hline
\end{tabular}

Notes: All models estimated with OLS and control for state demographics, state fixed effects, and year fixed effects. Insurance state sample includes the following states: $\mathrm{AK}, \mathrm{AL}, \mathrm{AR}, \mathrm{CO}, \mathrm{DC}, \mathrm{DE}, \mathrm{HI}, \mathrm{IA}, \mathrm{IL}, \mathrm{IN}, \mathrm{KS}, \mathrm{KY}, \mathrm{MA}, \mathrm{MD}$, ME, MO, MT, ND, NE, NH, NJ, NV, OR, PA, SC, SD, TN, TX, and UT. Standard errors are clustered at the state level and are reported in parentheses. The omitted year is 2013. Early expanding states excluded from the sample. $* * * ; * * *=$ statistically different from zero at the $1 \% ; 5 \% ; 10 \%$ level. 
Appendix Table 5C. Event study for payment source: TEDS 2010-2015

\begin{tabular}{lcccc}
\hline Outcome: & Private & Medicaid & Self-pay & $\begin{array}{c}\text { States and } \\
\text { localities }\end{array}$ \\
\hline $\begin{array}{l}\text { Pre-expansion proportion in } \\
\text { the expansion state group }\end{array}$ & 0.087 & 0.173 & 0.109 & 0.521 \\
\hline $2010 *$ treat & & & 0.063 & -0.082 \\
& 0.013 & 0.005 & $(0.042)$ & $(0.054)$ \\
$2011 *$ treat & $(0.013)$ & $0.032)$ & -0.050 & $(0.062)$ \\
& 0.019 & -0.005 & $(0.037)$ & -0.049 \\
$2012 *$ treat & $(0.013)$ & $(0.034)$ & 0.023 & $(0.041)$ \\
& 0.009 & 0.017 & $(0.023)$ & -0.093 \\
$2014 *$ treat & $(0.009)$ & $(0.030)$ & 0.005 & $(0.057)$ \\
$2015 *$ treat & 0.013 & 0.076 & $(0.028)$ & $-0.147 * *$ \\
& $(0.010)$ & $(0.048)$ & -0.012 & $(0.066)$ \\
\hline F-test of joint significance & 0.006 & $0.154 * *$ & $(0.054)$ & 0.3115 \\
of policy leads $(p$-value) & $(0.016)$ & $(0.062)$ & 0.4576 & 133 \\
\hline $\mathrm{N}$ & 0.5325 & 0.8641 & & 133 \\
\hline
\end{tabular}

Notes: All models estimated with OLS and control for state demographics, state fixed effects, and year fixed effects. Payment source state sample includes the following states: AK, AR, CO, DC, HI, IA, ID, KS, KY, MO, MS, MT, ND, NE, NH, NJ, NV, OH, PA, RI, SC, SD, TX, UT, and VT. Standard errors are clustered at the state level and are reported in parentheses. The omitted year is 2013. Early expanding states excluded from the sample. $* * * ; * * *=$ statistically different from zero at the $1 \% ; 5 \% ; 10 \%$ level. 
Appendix Table 5D. Event study for prescription medications financed by Medicaid: SDUD 2010-2015

\begin{tabular}{|c|c|}
\hline Outcome: & Prescriptions per 100,000 non-elderly adults \\
\hline Pre-expansion mean in the expansion state group & 806 \\
\hline \multirow[t]{2}{*}{ Treat $* 2011 \mathrm{Q} 1$} & 23.260 \\
\hline & $(98.965)$ \\
\hline \multirow[t]{2}{*}{ Treat *2011 Q2 } & 57.486 \\
\hline & $(111.705)$ \\
\hline \multirow[t]{2}{*}{ Treat $* 2011 \mathrm{Q} 3$} & 13.170 \\
\hline & $(109.795)$ \\
\hline \multirow[t]{2}{*}{ Treat $* 2011 \mathrm{Q} 4$} & 24.571 \\
\hline & $(97.958)$ \\
\hline \multirow[t]{2}{*}{ Treat $* 2012$ Q1 } & -36.105 \\
\hline & $(62.803)$ \\
\hline \multirow[t]{2}{*}{ Treat *2012 Q2 } & -14.334 \\
\hline & $(69.293)$ \\
\hline \multirow[t]{2}{*}{ Treat $* 2012$ Q3 } & -16.088 \\
\hline & $(75.358)$ \\
\hline \multirow[t]{2}{*}{ Treat $* 2012$ Q4 } & 8.701 \\
\hline & $(72.854)$ \\
\hline \multirow[t]{2}{*}{ Treat $* 2013 \mathrm{Q} 1$} & 41.583 \\
\hline & $(40.678)$ \\
\hline \multirow[t]{2}{*}{ Treat *2013 Q2 } & 76.230 \\
\hline & $(48.118)$ \\
\hline \multirow[t]{2}{*}{ Treat $* 2013 \mathrm{Q} 3$} & 14.219 \\
\hline & $(22.267)$ \\
\hline \multirow[t]{2}{*}{ Treat $* 2014$ Q1 } & $156.076^{*}$ \\
\hline & $(80.437)$ \\
\hline \multirow[t]{2}{*}{ Treat $* 2014 \mathrm{Q} 2$} & $306.145^{*}$ \\
\hline & $(152.557)$ \\
\hline \multirow[t]{2}{*}{ Treat $* 2014$ Q3 } & $499.113 * * *$ \\
\hline & $(165.335)$ \\
\hline \multirow[t]{2}{*}{ Treat $* 2014$ Q4 } & $393.790 * * *$ \\
\hline & $(111.150)$ \\
\hline \multirow[t]{2}{*}{ Treat $* 2015$ Q1 } & $438.059 * * *$ \\
\hline & $(128.960)$ \\
\hline \multirow[t]{2}{*}{ Treat *2015 Q2 } & $638.525 * * *$ \\
\hline & $(175.015)$ \\
\hline \multirow[t]{2}{*}{ Treat *2015 Q3 } & $618.154 * * *$ \\
\hline & $(164.769)$ \\
\hline \multirow[t]{2}{*}{ Treat *2015 Q4 } & $761.336 * * *$ \\
\hline & $(193.799)$ \\
\hline$F$-test of joint significance of policy leads ( $p$-value) & 0.2834 \\
\hline $\mathrm{N}$ & 896 \\
\hline
\end{tabular}

Notes: All models estimated with OLS and control for state demographics, state fixed effects, and period fixed effects. Standard errors are clustered at the state level and are reported in parentheses. The omitted period is 2013 Q4. Early expanding states excluded from the sample.

$* * * ; * * *=$ statistically different from zero at the $1 \% ; 5 \% ; 10 \%$ level. 
Appendix 6A. Effect of ACA Medicaid expansions on admissions per 100,000 non-elderly adults using alternative controls for between state heterogeneity: TEDS 2010-2015

\begin{tabular}{lc}
\hline \hline Outcome: & Admissions \\
\hline Pre-expansion mean in the expansion state group & 1062 \\
\hline Model (1) & 83.454 \\
& $(54.081)$ \\
\hline Model (2) & 88.942 \\
& $(58.583)$ \\
\hline Model (3) & $101.872^{*}$ \\
& $(57.340)$ \\
\hline N & 299 \\
\hline
\end{tabular}

Notes: All models estimated with OLS. Standard errors are clustered at the state level and are reported in parentheses. Model (1) controls for state demographics, state fixed effects, and period fixed effects (baseline model). Model (2) controls for state demographics, state-specific linear time trends, state fixed effects, and year fixed effects. Model (3) controls for state and year fixed effects.

$* * * ; * ; *=$ statistically different from zero at the $1 \% ; 5 \% ; 10 \%$ level.

Appendix 6B. Effect of ACA Medicaid expansions on insurance status using alternative controls for between state heterogeneity: TEDS 2010-2015

\begin{tabular}{lcccc}
\hline \hline Outcome: & Private & Medicaid & Other insurance & Uninsured \\
\hline $\begin{array}{l}\text { Pre-expansion proportion in } \\
\text { the expansion state group }\end{array}$ & 0.114 & 0.186 & 0.109 & 0.591 \\
\hline Model (1) & & & & \\
& 0.026 & $0.132^{* *}$ & 0.009 & $-0.166^{* * *}$ \\
\hline Model (2) & $(0.016)$ & $(0.048)$ & $(0.013)$ & $(0.034)$ \\
& 0.021 & 0.085 & 0.023 & $-0.128^{* * *}$ \\
\hline Model (3) & $(0.021)$ & $(0.055)$ & $(0.016)$ & $(0.035)$ \\
\hline $\mathrm{N}$ & 0.009 & $0.142^{* * *}$ & 0.008 & $-0.159^{* * *}$ \\
\hline
\end{tabular}

Notes: All models estimated with OLS. Standard errors are clustered at the state level and are reported in parentheses. Model (1) controls for state demographics, state fixed effects, and period fixed effects (baseline model). Model (2) controls for state demographics, state-specific linear time trends, state fixed effects, and year fixed effects. Model (3) controls for state and year fixed effects. Insurance state sample includes the following states: AK, AL, AR, CO, DC, DE, HI, IA, IL, IN, KS, KY, MA, MD, ME, MO, MT, ND, NE, NH, NJ, NV, OR, PA, SC, SD, TN, TX, and UT. Standard errors are clustered at the state level and are reported in parentheses. $* * * ; * ; *=$ statistically different from zero at the $1 \% ; 5 \% ; 10 \%$ level. 
Appendix Table 6C. Effect of ACA Medicaid expansions on payment source using alternative controls for between state heterogeneity: TEDS 2010-2015

\begin{tabular}{lcccc}
\hline \hline Outcome: & Private & Medicaid & Self-pay & $\begin{array}{c}\text { States and } \\
\text { localities }\end{array}$ \\
\hline $\begin{array}{l}\text { Pre-expansion proportion in } \\
\text { the expansion state group }\end{array}$ & 0.087 & 0.173 & 0.109 & 0.521 \\
\hline Model (1) & 0.015 & $0.129^{* * *}$ & -0.029 & $-0.115^{* *}$ \\
& $(0.012)$ & $(0.036)$ & $(0.025)$ & $(0.045)$ \\
\hline Model (2) & 0.012 & $0.117^{* * *}$ & -0.021 & $-0.108^{*}$ \\
& $(0.015)$ & $(0.036)$ & $(0.038)$ & $(0.055)$ \\
\hline Model (3) & 0.012 & $0.114^{* *}$ & -0.045 & -0.081 \\
& $(0.013)$ & $(0.049)$ & $(0.035)$ & $(0.051)$ \\
\hline $\mathrm{N}$ & 145 & 145 & 145 & 145 \\
\hline
\end{tabular}

Notes: All models estimated with OLS. Standard errors are clustered at the state level and are reported in parentheses. Model (1) controls for state demographics, state fixed effects, and period fixed effects (baseline model). Model (2) controls for state demographics, state-specific linear time trends, state fixed effects, and year fixed effects. Model (3) controls for state and year fixed effects. Payment source state sample includes the following states: AK, AR, CO, DC, HI, IA, ID, KS, KY, MO, MS, MT, ND, NE, NH, NJ, NV, OH, PA, RI, SC, SD, TX, UT, and VT. Standard errors are clustered at the state level and are reported in parentheses. $* * * ; * * * *=$ statistically different from zero at the $1 \% ; 5 \% ; 10 \%$ level.

Appendix Table 6D. Effect of ACA Medicaid expansions on prescription medications financed by Medicaid using alternative controls for between state heterogeneity: SDUD 2011-2015

\begin{tabular}{lc}
\hline \hline Outcome: & Prescriptions per 100,000 non-elderly adults \\
\hline Pre-expansion mean in the expansion state group & 806 \\
\hline Model (1) & $355.984^{* * *}$ \\
& $(109.328)$ \\
\hline Model (2) & $137.266^{* * *}$ \\
& $(44.641)$ \\
\hline Model (3) & $354.220^{* *}$ \\
& $(139.027)$ \\
\hline $\mathrm{N}$ & 1016 \\
\hline
\end{tabular}

Notes: All models estimated with OLS. Standard errors are clustered at the state level and are reported in parentheses. Model (1) controls for state demographics, state fixed effects, and period fixed effects (baseline model). Model (2) controls for state demographics, state-specific linear time trends, state fixed effects, and period fixed effects. Model (3) controls for state and period fixed effects. Standard errors are clustered at the state level and are reported in parentheses.

$* * * ; * ; *=$ statistically different from zero at the $1 \% ; 5 \% ; 10 \%$ level. 
Appendix Table 7A. Effect of ACA Medicaid expansions on admissions per 100,000 non-elderly adults using population weights: TEDS 2010-2015

\begin{tabular}{lc}
\hline Outcome: & Admissions \\
\hline Pre-expansion weighted mean in the expansion state group & 1126 \\
\hline DD & 23.563 \\
& $(44.785)$ \\
\hline $\mathrm{N}$ & 299 \\
\hline
\end{tabular}

Notes: All models estimated with OLS and control for state demographics, state fixed effects, and year fixed effects. Regressions are weighted by the state non-elderly adult population. Standard errors are clustered at the state level and are reported in parentheses.

$* * * * * ; *=$ statistically different from zero at the $1 \% ; 5 \% ; 10 \%$ level.

Appendix Table 7B. Effect of ACA Medicaid expansions on insurance status using population weights: TEDS 2010-2015

\begin{tabular}{lcccc}
\hline \hline Outcome: & Private & Medicaid & Other insurance & Uninsured \\
\hline $\begin{array}{l}\text { Pre-expansion weighted } \\
\text { proportion in the expansion }\end{array}$ & 0.113 & 0.206 & 0.126 & 0.555 \\
state group & & & & \\
\hline DD & $0.049^{* *}$ & $0.093^{*}$ & 0.009 & $-0.150^{* * *}$ \\
& $(0.019)$ & $(0.046)$ & $(0.018)$ & $(0.032)$ \\
\hline $\mathrm{N}$ & 169 & 169 & 169 & 169 \\
\hline
\end{tabular}

Notes: All models estimated with OLS and control for state demographics, state fixed effects, and year fixed effects. Regressions are weighted by the state non-elderly adult population. Insurance state sample includes the following states: AK, AL, AR, CO, DC, DE, HI, IA, IL, IN, KS, KY, MA, MD, ME, MO, MT, ND, NE, NH, NJ, NV, OR, $\mathrm{PA}, \mathrm{SC}, \mathrm{SD}, \mathrm{TN}, \mathrm{TX}$, and UT. Standard errors are clustered at the state level and are reported in parentheses. $* * * ; * * *=$ statistically different from zero at the $1 \% ; 5 \% ; 10 \%$ level.

Appendix Table 7C. Effect of ACA Medicaid expansions on payment source using population weights: TEDS 2010-2015

\begin{tabular}{lcccc}
\hline \hline Outcome: & Private & Medicaid & Self-pay & $\begin{array}{c}\text { States and } \\
\text { localities }\end{array}$ \\
\hline $\begin{array}{l}\text { Pre-expansion weighted } \\
\text { proportion in the expansion }\end{array}$ & 0.066 & 0.157 & 0.149 & 0.628 \\
state group & & & & $-0.167 * * *$ \\
\hline DD & & & -0.014 & $(0.036)$ \\
\hline $\mathrm{N}$ & $0.030 * * *$ & $0.152^{* * *}$ & 145 & 145 \\
\hline
\end{tabular}

Notes: All models estimated with OLS and control for state demographics, state fixed effects, and year fixed effects. Regressions are weighted by the state non-elderly adult population. Payment source state sample includes the following states: AK, AR, CO, DC, HI, IA, ID, KS, KY, MO, MS, MT, ND, NE, NH, NJ, NV, OH, PA, RI, SC, SD, TX, UT, and VT. Standard errors are clustered at the state level and are reported in parentheses. $* * * ; * * ;=$ statistically different from zero at the $1 \% ; 5 \% ; 10 \%$ level. 
Appendix Table 7D. Effect of ACA Medicaid expansions on prescription medications financed by Medicaid using population weights: SDUD 2011-2015

\begin{tabular}{lc}
\hline \hline Outcome: & Prescriptions per 100,000 non-elderly adults \\
\hline Pre-expansion weighted mean in the expansion state group & 684 \\
\hline DD & $216.381^{* * *}$ \\
& $(80.230)$ \\
\hline N & 1016
\end{tabular}

Notes: All models estimated with OLS and control for state demographics, state-specific linear time trends, state fixed effects, and period fixed effects. Regressions are weighted by the state non-elderly adult population. Standard errors are clustered at the state level and are reported in parentheses.

$* * * ; * ; *=$ statistically different from zero at the $1 \% ; 5 \% ; 10 \%$ level.

Appendix Table 8A. Effect of ACA Medicaid expansions on admissions per 100,000 non-elderly adults excluding criminal justice system referrals: TEDS 2010-2015

\begin{tabular}{lc}
\hline \hline Outcome: & Admissions \\
\hline Pre-expansion mean in the expansion state group & 702 \\
\hline DD & 62.437 \\
& $(41.570)$ \\
\hline $\mathrm{N}$ & 299 \\
\hline
\end{tabular}

Notes: All models estimated with OLS and control for state demographics, state fixed effects, and year fixed effects. Standard errors are clustered at the state level and are reported in parentheses.

$* * * ; * * * *=$ statistically different from zero at the $1 \% ; 5 \% ; 10 \%$ level.

Appendix Table 8B. Effect of ACA Medicaid expansions on insurance status excluding criminal justice system referrals: TEDS 2010-2015

\begin{tabular}{lcccc}
\hline Outcome: & Private & Medicaid & Other insurance & Uninsured \\
\hline $\begin{array}{l}\text { Pre-expansion proportion in } \\
\text { the expansion state group }\end{array}$ & 0.111 & 0.208 & 0.115 & 0.566 \\
\hline DD & & & & -0.004 \\
& $0.036^{*}$ & $0.136^{* *}$ & $(0.017)$ & $-0.169^{* * *}$ \\
\hline $\mathrm{N}$ & $(0.018)$ & $(0.053)$ & 169 & $(0.034)$ \\
\hline
\end{tabular}

Notes: All models estimated with OLS and control for state demographics, state fixed effects, and year fixed effects. Insurance state sample includes the following states: AK, AL, AR, CO, DC, DE, HI, IA, IL, IN, KS, KY, MA, MD, ME, MO, MT, ND, NE, NH, NJ, NV, OR, PA, SC, SD, TN, TX, and UT. Standard errors are clustered at the state level and are reported in parentheses.

$* * * ; * ; *=$ statistically different from zero at the $1 \% ; 5 \% ; 10 \%$ level.

Appendix Table 8C. Effect of ACA Medicaid expansions on payment source excluding criminal justice system referrals: TEDS 2010-2015

\begin{tabular}{lcccc}
\hline \hline Outcome: & Private & Medicaid & Self-pay & $\begin{array}{c}\text { States and } \\
\text { localities }\end{array}$ \\
\hline $\begin{array}{l}\text { Pre-expansion proportion in } \\
\text { the expansion state group }\end{array}$ & 0.0975 & 0.191 & 0.190 & 0.522 \\
\hline DD & & & -0.033 & $-0.133^{* * *}$ \\
& 0.020 & $0.146^{* * *}$ & $(0.023)$ & $(0.046)$ \\
\hline $\mathrm{N}$ & $(0.018)$ & $(0.039)$ & 140 & 140
\end{tabular}

Notes: All models estimated with OLS and control for state demographics, state fixed effects, and year fixed effects. Payment source state sample includes the following states: AK, AR, CO, DC, HI, IA, ID, KS, KY, MO, MS, MT, ND, NE, NH, NJ, NV, OH, PA, RI, SC, SD, TX, UT, and VT. Standard errors are clustered at the state level and are reported in parentheses.

$* * * ; * * *=$ statistically different from zero at the $1 \% ; 5 \% ; 10 \%$ level. 


\section{References:}

Akosa Antwi, Y., A. S. Moriya and K. Simon (2013). "Effects of federal policy to insure young adults: Evidence from the 2010 affordable care act's dependent-coverage mandate." American Economic Journal: Economic Policy 5(4): 1-28.

Anderson, D. M. (2010). "Does information matter? The effect of the meth project on meth use among youths." Journal of Health Economics 29(5): 732-742.

Anderson, D. M., B. Hansen and D. I. Rees (2013). "Medical marijuana laws, traffic fatalities, and alcohol consumption." Journal of Law \& Economics 56(2): 333-369.

Andrews, C., A. Abraham, C. M. Grogan, H. A. Pollack, C. Bersamira, K. Humphreys and P. Friedmann (2015). "Despite resources from the aca, most states do little to help addiction treatment programs implement health care reform." Health Affairs 34(5): 828-835.

Angrist, J. D. and J. Pischke (2009). Mostly harmless econometrics: An empiricist's companion. Princeton, NJ, Princeton University Press.

Antonisse, L., R. L. Garfield, R. Rudowitz and S. Artiga (2016). The effects of medicaid expansion under the aca: Findings from a literature review. The Kaiser Commission on Medicaid and the uninsured. K. F. Foundation. Melno Park, CA, Kaiser Family Foundation.

Autor, D. H. (2003). "Outsourcing at will: The contribution of unjust dismissal doctrine to the growth of employment outsourcing." Journal of Labor Economics 21(1): 1-42.

Balsa, A. I., M. T. French, J. C. Maclean and E. C. Norton (2009). "From pubs to scrubs:

Alcohol misuse and health care use." Health Services Research 44(5): 1480-1503.

Beronio, K., S. Glied and R. Frank (2014). "How the affordable care act and mental health parity and addiction equity act greatly expand coverage of behavioral health care." The Journal of Behavioral Health Services \& Research 41(4): 410-428.

Bertrand, M., E. Duflo and S. Mullainathan (2004). "How much should we trust differences-indifferences estimates?" Quarterly Journal of Economics 119(1): 249-275.

Boone, M., N. J. Brown, M. A. Moon, D. J. Schuman, J. Thomas and D. L. Wright (2004).

"Clinical guidelines for the use of buprenorphine in the treatment of opioid addiction. Treatment improvement protocol (tip) series 40." $\underline{\text { Substance Abuse and Mental Health Services }}$

Administration.

Bouchery, E., R. Harwood, R. Malsberger, E. Caffery, J. Nysenbaum and K. Hourihan (2012).

"Medicaid substance abuse treatment spending: Findings report." Mathematic Policy Research. Buck, J. A. (2011). "The looming expansion and transformation of public substance abuse treatment under the affordable care act." Health Affairs 30(8): 1402-1410.

Busch, S. H., E. Meara, H. A. Huskamp and C. L. Barry (2013). "Characteristics of adults with substance use disorders expected to be eligible for medicaid under the aca." Psychiatric Services 64(6): 520-526.

Cameron, C. A. and D. L. Miller (2015). "A practitioner's guide to cluster-robust inference." Journal of Human Resources 50(2): 317-372.

Carpenter, C. S. (2005). "Heavy alcohol use and the commission of nuisance crime: Evidence from underage drunk driving laws." American Economic Review 95(2): 267-272.

Carr, C. J., J. M. Xu, C. Redko, D. T. Lane, R. C. Rapp, J. Goris and R. G. Carlson (2008). "Individual and system influences on waiting time for substance abuse treatment." Journal of Substance Abuse Treatment 34(2): 192-201. 
Case, A. and A. Deaton (2015). "Rising morbidity and mortality in midlife among white nonhispanic americans in the 21st century." Proceedings of the National Academy of Sciences 112(49): 15078-15083.

Caulkins, J. P., A. Kasunic and M. A. Lee (2014). "Societal burden of substance abuse." International Public Health Journal 6(3): 269-282.

Center for Behavioral Health Statistics and Quality (2015). Behavioral health trends: Results from the 2014 national survey on drug use and health. Rockville, MD, Center for Behavioral Health Statistics and Quality.

Center for Behavioral Health Statistics and Quality (2016). Key substance use and mental health indicators in the united states: Results from the 2015 national survey on drug use and health.

Rockville, MD, Key substance use and mental health indicators in the united states: Results from the 2015 national survey on drug use and health.

Centers for Disease Control and Prevention (2016). Opioid overdose: Understanding the epidemic. C. f. D. C. a. Prevention. Atlanta, GA, Centers for Disease Control and Prevention. Cole, M. B., O. Galárraga, I. B. Wilson, B. Wright and A. N. Trivedi (2017). "At federally funded health centers, medicaid expansion was associated with improved quality of care." Health Affairs 36(1): 40-48.

Congressional Budget Office (2017a). American health care act. Washington, DC, Congressional Budget Office.

Congressional Budget Office (2017b). Congrsessional budget office cost estimate: H.R. 1628 better care reconciliation act of 2017. Washington, DC, Congressional Budget Office.

Courtemanche, C., J. Marton, B. Ukert, A. Yelowitz and D. Zapata (2017a). Early effects of the affordable care act on healthcare access, risky health behaviors, and self-assessed health. National Bureau of Economic Research Working Paper Series. Cambridge, MA.

Courtemanche, C., J. Marton, B. Ukert, A. Yelowitz and D. Zapata (2017b). "Early impacts of the affordable care act on health insurance coverage in medicaid expansion and non-expansion states." Journal of Policy Analysis and Management 36(1): 178-210.

Dave, D. and S. Mukerjee (2011). "Mental health parity legislation, cost-sharing and substanceabuse treatment admissions." Health Economics 20(2): 161-183.

Decker, S. L., D. Kostova, G. M. Kenney and S. K. Long (2013). "Health status, risk factors, and medical conditions among persons enrolled in medicaid vs uninsured low-income adults potentially eligible for medicaid under the affordable care act." JAMA 309(24): 2579-2586. Finkelstein, A. (2007). "The aggregate effects of health insurance: Evidence from the introduction of medicare." Quarterly Journal of Economics 122(1): 1-37.

Flood, S., M. King, S. Ruggles and J. R. Warren (2017). Integrated public use microdata series, current population survey. Minneapolis, MN.

Frank, R. G. and S. Glied (2017). "Keep obamacare to keep progress on treating opioid disorders and mental illnesses." The Hill http://thehill.com/blogs/pundits-blog/healthcare/313672-keepobamacare-to-keep-progress-on-treating-opioid-disorders 2017.

Frean, M., J. Gruber and B. D. Sommers (2017). "Premium subsidies, the mandate, and medicaid expansion: Coverage effects of the affordable care act." Journal of Health Economics 53: 72-86. French, M. T., H. Fang and A. I. Balsa (2011). "Longitudinal analysis of changes in illicit drug use and health services utilization." Health Services Research 46(3): 877-899.

French, M. T., J. Homer, G. Gumus and L. Hickling (2016). "Key provisions of the patient protection and affordable care act (aca): A systematic review and presentation of early research findings." Health Services Research 51(5): 1735-1771. 
Gfroerer, J., J. Bose, D. Trunzo, A. Strashny, K. Batts and M. Pemberton (2014). Estimating substance abuse treatment: A comparison of data from a household survey, a facility survey, and an administrative data set. Rockville, MD.

Glied, S. and J. G. Zivin (2002). "How do doctors behave when some (but not all) of their patients are in managed care?" Journal of Health Economics 21(2): 337-353.

Hasin, D. S., C. P. O’Brien, M. Auriacombe, G. Borges, K. Bucholz, A. Budney, W. M. Compton, T. Crowley, W. Ling and N. M. Petry (2013). "Dsm-5 criteria for substance use disorders: Recommendations and rationale." American Journal of Psychiatry 170(8): 834-851. Hu, L., R. Kaestner, B. Mazumder, S. Miller and A. Wong (2016). The effect of the patient protection and affordable care act medicaid expansions on financial well-being. Nationa Bureau of Economic Research. Cambridge, MA, National Bureau of Economic Research.

Jayakody, R., S. Danziger and H. Pollack (2000). "Welfare reform, substance use, and mental health." Journal of Health Politics, Policy and Law 25(4): 623-652.

Jones, C. M., M. Campopiano, G. Baldwin and E. McCance-Katz (2015). "National and state treatment need and capacity for opioid agonist medication-assisted treatment." American Journal of Public Health 105(8): e55-e63.

Kirby, J. B. and J. P. Vistnes (2016). "Access to care improved for people who gained medicaid or marketplace coverage in 2014." Health Affairs 35(10): 1830-1834.

Lo Sasso, A. T. and B. D. Meyer (2006). The health care safety net and crowd-out of private health insurance. National Bureau of Economic Research Working Paper Series. Cambridge, MA, National Bureau of Economic Research.

Lu, M. and T. G. McGuire (2002). "The productivity of outpatient treatment for substance abuse." The Journal of Human Resources 37(2): 309-335.

Maclean, J. C., M. F. Pesko and S. C. Hill (2017). The effect of insurance expansions on smoking cessation medication use: Evidence from recent medicaid expansions. National Bureau of Economic Research Working Paper Series. Cambridge, MA, National Bureau of Economic Research.

Maclean, J. C. and B. Saloner (2017). "Substance use treatment provider behavior and healthcare reform: Evidence from massachusetts." Health Economics: n/a-n/a.

Mark, T. L., T. Yee, K. R. Levit, J. Camacho-Cook, E. Cutler and C. D. Carroll (2016).

"Insurance financing increased for mental health conditions but not for substance use disorders, 1986-2014." Health Affairs 35(6): 958-965.

Markowitz, S. and M. Grossman (2000). "The effects of beer taxes on physical child abuse." Journal of Health Economics 19(2): 271-282.

McLellan, A. T. and K. Meyers (2004). "Contemporary addiction treatment: A review of systems problems for adults and adolescents." Biological Psychiatry 56(10): 764-770.

McLellan, A. T. and A. M. Woodworth (2014). "The affordable care act and treatment for "substance use disorders:" implications of ending segregated behavioral healthcare." Journal of Substance Abuse Treatment 46(5): 541-545.

Miller, S. and L. R. Wherry (2017). "Health and access to care during the first 2 years of the aca medicaid expansions." New England Journal of Medicine 376(10): 947-956.

Mulcahy, A. W., C. Eibner and K. Finegold (2016). "Gaining coverage through medicaid or private insurance increased prescription use and lowered out-of-pocket spending." Health Affairs 35(9): 1725-1733.

National Institute on Drug Abuse (2012). Principles of drug addiction treatment: A researchbased guide. Besthesa, MD, National Insitutes of Health. 
Nikpay, S., T. Buchmueller and H. G. Levy (2016). "Affordable care act medicaid expansion reduced uninsured hospital stays in 2014." Health Affairs 35(1): 106-110.

Office of National Drug Control Policy (2012). What america's users spend on illegal drugs, 2000-2006. Washington, DC, Executive Office of the President.

Office of the Inspector General Commonwealth of Massachusetts (2016). Masshealth's administration of certain medicaid and health safety net schedule ii drug claims. Boston, MA, Commonwealth of Massachusetts.

Pacula, R. L., D. Powell, P. Heaton and E. L. Sevigny (2015). "Assessing the effects of medical marijuana laws on marijuana use: The devil is in the details." Journal of Policy Analysis and Management 34(1): 7-31.

Polsky, D., M. Candon, B. Saloner and et al. (2017). "Changes in primary care access between 2012 and 2016 for new patients with medicaid and private coverage." JAMA Internal Medicine 177(4): 588-590.

Popovici, I. and M. T. French (2013). Economic evaluation of substance abuse interventions: Overview of recent research findings and policy implications. Addictions: A comprehensive guidebook. B. S. McCrady and E. E. Epstein. Oxford, U.K., Oxford University Press. 2. Powell, D., R. L. Pacula and M. Jacobson (2015). Do medical marijuana laws reduce addictions and deaths related to pain killers?, National Bureau of Economic Research.

Rajkumar, A. S. and M. T. French (1997). "Drug abuse, crime costs, and the economic benefits of treatment." Journal of Quantitative Criminology 13(3): 291-323.

Rudowitz, R., S. Artiga and M. Musumeci (2014). The aca and recent section 1115 medicaid demonstration waivers K. F. Foundation. Melno Park, CA, Kaiser Family Foundation.

Saloner, B. (2017). "An update on "insurance coverage and treatment use under the affordable care act among adults with mental and substance use disorders"." Psychiatric Services 68(3): 310-311.

Saloner, B., Y. Akosa Antwi, J. C. Maclean and B. Cook (2017). "Access to health insurance and utilization of substance use disorder treatment: Evidence from the affordable care act dependent coverage provision." Health Economics: n/a-n/a.

Saloner, B., S. Bandara, M. A. Bachhuber and C. L. Barry (2017). "Insurance coverage and treatment use under the affordable care act among adults with mental and substance use disorders." Psychiatric Services 0(0): appi.ps.201600182.

Simon, K., A. Soni and J. Cawley (2017). "The impact of health insurance on preventive care and health behaviors: Evidence from the first two years of the aca medicaid expansions." Journal of Policy Analysis and Management 36(2): 390-417.

Sloan, F., J. Mitchell and J. Cromwell (1978). "Physician participation in state medicaid programs." Journal of Human Resources 13 Suppl: 211-245.

Sojourner, A. and E. Golberstein. (2017). "Medicaid expansion reduced unpaid medical debt and increased financial satisfaction." Health Affairs Blog: Following the ACA Retrieved August 1, 2017, from http://healthaffairs.org/blog/2017/07/24/medicaid-expansion-reduced-unpaidmedical-debt-and-increased-financial-satisfaction/.

Solon, G., S. J. Haider and J. M. Wooldridge (2015). "What are we weighting for?" Journal of Human Resources 50(2): 301-316.

Sommers, B. D., E. Arntson, G. M. Kenney and A. M. Epstein (2013). "Lessons from early medicaid expansions under health reform: Interviews with medicaid officials." Medicare Medicaid Res Rev 3(4). 
Sommers, B. D., R. J. Blendon, E. Orav and A. M. Epstein (2016a). "Changes in utilization and health among low-income adults after medicaid expansion or expanded private insurance." JAMA Internal Medicine 176(10): 1501-1509.

Sommers, B. D., R. J. Blendon and E. J. Orav (2016b). "Both the 'private option' and traditional medicaid expansions improved access to care for low-income adults." Health Affairs 35(1): 96105.

Substance Abuse and Mental Health Services Administration (2010). National survey of substance abuse treatment services (n-ssats), 2009. Rockville, MD.

Substance Abuse and Mental Health Services Administration (2016). Characteristics of criminal justice system referrals discharged from substance abuse treatment and facilities with specialty designed criminal justice programs. Rockville, MD, Substance Abuse and Mental Health Services Administration.

Substance Abuse and Mental Health Services Administration (2017). Treatment episode data set admissions (teds-a) concatenated, 2010 to 2015 data set 5 (ds5) S. A. a. M. H. S. Administration. Rockville, MD.

Swensen, I. D. (2015). "Substance-abuse treatment and mortality." Journal of Public Economics 122: $13-30$.

Terza, J. V. (2002). "Alcohol abuse and employment: A second look." Journal of Applied Econometrics 17(4): 393-404.

U.S. Department of Health and Human Services (2012). States' collection of rebates for drugs paid through medicaid managed care organizations. Washington, DC, U.S. Department of Health and Human Services, Office of Inspector General.

United Nations Office on Drugs and Crime (2011). The non-medical use of prescription drugs: Policy direction issues. United Nations Discussion Paper Series. U. Nations. New York, NY, United Nations.

University of Kentucky Center for Poverty Research Center (2016). State level data of economic, political, and transfer program information for 1980-2015. Lexington, KY.

Wen, H., B. G. Druss and J. R. Cummings (2015). "Effect of medicaid expansions on health insurance coverage and access to care among low-income adults with behavioral health conditions." Health Services Research 50(6): 1787-1809.

Wen, H., J. M. Hockenberry, T. F. Borders and B. G. Druss (2017). "Impact of medicaid expansion on medicaid-covered utilization of buprenorphine for opioid use disorder treatment." Medical Care 55(4): 336-341.

Wen, H., J. M. Hockenberry and J. R. Cummings (2014). The effect of substance use disorder treatment use on crime: Evidence from public insurance expansions and health insurance parity mandates, National Bureau of Economic Research.

Wherry, L. R. and S. Miller (2016). "Early coverage, access, utilization, and health effects associated with the affordable care act medicaid expansions: A quasi-experimental study." Annals of Internal Medicine 164(12): 795-803.

World Health Organization. (2017). "Management of substance abuse: The global burden." Retrieved February 21, 2017, from http://www.who.int/substance_abuse/facts/global_burden/en/. 
Supplementary tables for Maclean \& Saloner (2017)

Supplementary Table 1A. Effect of ACA Medicaid expansions on admissions per 100,000 non-elderly adults using the balanced panel of states: TEDS 2010-2015

\begin{tabular}{lc}
\hline \hline Outcome: & Admissions \\
\hline Pre-expansion mean in the expansion state group & 1058 \\
\hline DD & $104.411^{*}$ \\
& $(53.615)$ \\
\hline $\mathrm{N}$ & 270 \\
\hline
\end{tabular}

Notes: All models estimated with OLS and control for state demographics, state fixed effects, and year fixed effects. Excluded states include: GA, MS,OR, PA, and SC. Standard errors are clustered at the state level and are reported in parentheses.

$* * * ; * * *=$ statistically different from zero at the $1 \% ; 5 \% ; 10 \%$ level.

Supplementary Table 1B. Effect of ACA Medicaid expansions on insurance status using the balanced panel of states: TEDS 2010-2015

\begin{tabular}{lcccc}
\hline \hline Outcome: & Private & Medicaid & Other insurance & Uninsured \\
\hline $\begin{array}{l}\text { Pre-expansion proportion in } \\
\text { the expansion state group }\end{array}$ & 0.116 & 0.200 & 0.081 & 0.602 \\
\hline $\mathrm{DD}$ & & & & $-0.158^{* * *}$ \\
& $0.027^{*}$ & $0.113^{* *}$ & 0.018 & $(0.035)$ \\
\hline $\mathrm{N}$ & $(0.016)$ & $(0.048)$ & $(0.012)$ & 150 \\
\hline
\end{tabular}

Notes: All models estimated with OLS and control for state demographics, state fixed effects, and year fixed effects. Excluded states include: GA, MS, OR, PA, and SC. Insurance state sample includes the following states: AK, AL, AR, CO, DC, DE, HI, IA, IL, IN, KS, KY, MA, MD, ME, MO, MT, ND, NE, NH, NJ, NV, SD, TN, TX, and UT. Standard errors are clustered at the state level and are reported in parentheses.

$* * * ; * ; *=$ statistically different from zero at the $1 \% ; 5 \% ; 10 \%$ level.

Supplementary Table 1C. Effect of ACA Medicaid expansions on payment source using the balanced panel of states: TEDS 2010-2015

\begin{tabular}{|c|c|c|c|c|}
\hline Outcome: & Private & Medicaid & Self-pay & $\begin{array}{c}\text { States and } \\
\text { localities }\end{array}$ \\
\hline $\begin{array}{l}\text { Pre-expansion proportion in } \\
\text { the expansion state group }\end{array}$ & 0.089 & 0.171 & 0.237 & 0.503 \\
\hline $\mathrm{DD}$ & $\begin{array}{c}0.010 \\
(0.014) \\
\end{array}$ & $\begin{array}{l}0.135 * * * \\
(0.033) \\
\end{array}$ & $\begin{array}{l}-0.028 \\
(0.029) \\
\end{array}$ & $\begin{array}{c}-0.118 * * \\
(0.048)\end{array}$ \\
\hline $\mathrm{N}$ & 126 & 126 & 126 & 126 \\
\hline
\end{tabular}

Notes: All models estimated with OLS and control for state demographics, state fixed effects, and year fixed effects. Excluded states include: GA, MS, OR, PA, and SC. Payment source state sample includes the following states: AK, AR, CO, DC, HI, IA, ID, KS, KY, MO, MT, ND, NE, NH, NJ, NV, OH, RI, SD, TX, UT, and VT. Standard errors are clustered at the state level and are reported in parentheses.

$* * * ; * ; *=$ statistically different from zero at the $1 \% ; 5 \% ; 10 \%$ level. 
Supplementary Table 2. Effect of ACA Medicaid expansions on prescription medications financed by Medicaid per 100,000 non-elderly adults: SDUD 2010-2015

\begin{tabular}{lc}
\hline \hline Outcome: & Prescriptions \\
\hline Pre-expansion mean in the expansion state group & 734 \\
\hline DD & $346.213^{* * *}$ \\
& $(105.640)$ \\
\hline $\mathrm{N}$ & 1220 \\
\hline
\end{tabular}

Notes: All models estimated with OLS and control for state demographics, state fixed effects, and period fixed effects. Standard errors are clustered at the state level and are reported in parentheses.

$* * * ; * ; *=$ statistically different from zero at the $1 \% ; 5 \% ; 10 \%$ level.

Supplementary Table 3. Effect of ACA Medicaid expansions on prescription medications financed by Medicaid per 100,000 non-elderly adults excluding five states with odd missing data patterns: SDUD 20112015

\begin{tabular}{lc}
\hline \hline Outcome: & Prescriptions \\
\hline Pre-expansion mean in the expansion state group & 840 \\
\hline DD & $414.056^{* * *}$ \\
& $(115.276)$ \\
\hline N & 920 \\
\hline
\end{tabular}

Notes: All models estimated with OLS and control for state demographics, state fixed effects, and period fixed effects. States with odd missing data patterns include: AZ, HI, OH, RI, and VA. Standard errors are clustered at the state level and are reported in parentheses.

$* * * ; * * *=$ statistically different from zero at the $1 \% ; 5 \% ; 10 \%$ level.

Supplementary Table 4. Effect of ACA Medicaid expansions on prescription medications financed by Medicaid per 100,000 non-elderly adults aggregating the data to the annual level: SDUD 2011-2015

\begin{tabular}{lc}
\hline \hline Outcome: & Prescriptions \\
\hline Pre-expansion mean in the expansion state group & 3222 \\
\hline DD & $1559.263^{* * *}$ \\
& $(540.162)$ \\
\hline $\mathrm{N}$ & 254 \\
\hline
\end{tabular}

Notes: All models estimated with OLS and control for state demographics, state fixed effects, and year fixed effects. Standard errors are clustered at the state level and are reported in parentheses.

$* * * ; * ; *=$ statistically different from zero at the $1 \% ; 5 \% ; 10 \%$ level.

Supplementary Table 5. Effect of ACA Medicaid expansions on the probability of missing data: SDUD 20112015

\begin{tabular}{lc}
\hline \hline Outcome: & Prob(missing data) \\
\hline Pre-expansion proportion in the expansion state group & 0.133 \\
\hline Expansion state & 0.263 \\
& $(0.438)$ \\
\hline $\mathrm{N}$ & 51
\end{tabular}

Notes: States with odd missing data patterns include: AZ, HI, OH, RI, and VA. Data are aggregated to the state-level (outcome is fixed within state over the study period). All models estimated with and OLS and control for state demographics. Standard errors are clustered at the state level and are reported in parentheses.

$* * * ; * ; *=$ statistically different from zero at the $1 \% ; 5 \% ; 10 \%$ level. 
Supplementary Table 6A. Effect of ACA Medicaid expansions on admissions per 100,000 non-elderly adults using alternative expansion coding schemes: TEDS 2010-2015

\begin{tabular}{lc}
\hline \hline Outcome: & Admissions \\
\hline Pre-expansion mean in the expansion state group & 1011 \\
\hline Maclean et al (2017) & 69.258 \\
& $(58.601)$ \\
\hline $\mathrm{N}$ & 299 \\
\hline Pre-expansion mean in the expansion state group & 912 \\
\hline Wherry \& Miller (2016) exclusions + & 49.724 \\
& $(56.821)$ \\
\hline $\mathrm{N}$ & 269 \\
\hline
\end{tabular}

Notes: All models estimated with OLS and control for state demographics, state fixed effects, and year fixed effects. Standard errors are clustered at the state level and are reported in parentheses.

+Excluded states include: DC, DE, MA, NY, and VT.

$* * * ; * ; *=$ statistically different from zero at the $1 \% ; 5 \% ; 10 \%$ level.

Supplementary Table 6B. Effect of ACA Medicaid expansions on insurance status using alternative expansion coding schemes: TEDS 2010-2015

\begin{tabular}{lcccc}
\hline \hline Outcome: & Private & Medicaid & Other insurance & Uninsured \\
\hline $\begin{array}{l}\text { Pre-expansion mean in the } \\
\text { expansion state group }\end{array}$ & 0.127 & 0.164 & 0.096 & 0.612 \\
\hline Maclean et al (2017) & 0.017 & $0.168^{* * *}$ & 0.006 & $-0.191 * * *$ \\
& $(0.017)$ & $(0.042)$ & $(0.013)$ & $(0.032)$ \\
\hline $\mathrm{N}$ & 169 & 169 & 0.116 & 169 \\
\hline $\begin{array}{l}\text { Pre-expansion mean in the } \\
\text { expansion state group }\end{array}$ & 0.119 & 0.161 & & 0.604 \\
\hline $\begin{array}{l}\text { Wherry \& Miller (2016) } \\
\text { exclusions + }\end{array}$ & $0.035^{*}$ & $0.140^{* *}$ & 0.012 & $-0.187^{* * *}$ \\
\hline $\mathrm{N}$ & $(0.018)$ & $(0.050)$ & $(0.013)$ & $(0.036)$ \\
\hline
\end{tabular}

Notes: All models estimated with OLS and control for state demographics, state fixed effects, and year fixed effects. Insurance state sample includes the following states: AK, AL, AR, CO, DC, DE, HI, IA, IL, IN, KS, KY, MA, MD, ME, MO, MT, ND, NE, NH, NJ, NV, OR, PA, SC, SD, TN, TX, and UT. Standard errors are clustered at the state level and are reported in parentheses.

+Excluded states include: DC, DE, MA, NY, and VT.

$* * * ; * ; *=$ statistically different from zero at the $1 \% ; 5 \% ; 10 \%$ level. 
Supplementary Table 6C. Effect of ACA Medicaid expansions on payment source using alternative expansion coding schemes: TEDS 2010-2015

\begin{tabular}{lcccc}
\hline \hline Outcome: & Private & Medicaid & Self-pay & $\begin{array}{c}\text { States and } \\
\text { localities }\end{array}$ \\
\hline $\begin{array}{l}\text { Pre-expansion mean in the } \\
\text { expansion state group }\end{array}$ & 0.087 & 0.127 & 0.247 & 0.539 \\
\hline Maclean et al (2017) & 0.007 & $0.129^{* * *}$ & -0.033 & $-0.103^{* *}$ \\
& $(0.011)$ & $(0.041)$ & $(0.028)$ & $(0.046)$ \\
\hline $\mathrm{N}$ & 145 & 145 & 145 & 145 \\
\hline $\begin{array}{l}\text { Pre-expansion mean in the } \\
\text { expansion state group }\end{array}$ & 0.082 & 0.137 & 0.232 & 0.548 \\
\hline $\begin{array}{l}\text { Wherry \& Miller (2016) } \\
\text { exclusions }+\end{array}$ & $0.026^{* *}$ & $0.140^{* * *}$ & -0.026 & $-0.141^{* * *}$ \\
\hline $\mathrm{N}$ & $(0.010)$ & $(0.037)$ & $(0.027)$ & $(0.046)$ \\
\hline
\end{tabular}

Notes: All models estimated with OLS and control for state demographics, state fixed effects, and year fixed effects. Payment source state sample includes the following states: AK, AR, CO, DC, HI, IA, ID, KS, KY, MO, MS, MT, ND, NE, NH, NJ, NV, OH, PA, RI, SC, SD, TX, UT, and VT. Standard errors are clustered at the state level and are reported in parentheses.

+Excluded states include: DC, DE, MA, NY, and VT.

$* * * ; * * ;=$ statistically different from zero at the $1 \% ; 5 \% ; 10 \%$ level.

Supplementary Table 6D. Effect of ACA Medicaid expansions on prescription medications financed by Medicaid per 100,000 non-elderly adults using alternative expansion coding schemes: SDUD 2011-2015

\begin{tabular}{lc}
\hline \hline Outcome: & Prescriptions \\
\hline Pre-expansion mean in the expansion state group & 539 \\
\hline Maclean et al (2017) & $257.462^{* *}$ \\
& $(118.055)$ \\
\hline $\mathrm{N}$ & 1016 \\
\hline Pre-expansion mean in the expansion state group & 558 \\
\hline Wherry \& Miller (2016) exclusions + & $306.951^{* * *}$ \\
& $(103.793)$ \\
\hline $\mathrm{N}$ & 916
\end{tabular}

Notes: All models estimated with OLS and control for state demographics, state fixed effects, and period fixed effects. Standard errors are clustered at the state level and are reported in parentheses.

+Excluded states include: DC, DE, MA, NY, and VT.

$* * * ; * * ; *=$ statistically different from zero at the $1 \% ; 5 \% ; 10 \%$ level. 
Supplementary Table 7A. Effect of ACA Medicaid expansions on insurance status using alternative missingness thresholds: TEDS 2010-2015

\begin{tabular}{lcccc}
\hline \hline Outcome: & Private & Medicaid & Other insurance & Uninsured \\
\hline $\begin{array}{l}\text { Pre-expansion proportion in } \\
\text { the expansion state group }\end{array}$ & 0.119 & 0.195 & 0.111 & 0.574 \\
\hline $\begin{array}{l}\text { No more than 15\% missing } \\
\text { in any year }\end{array}$ & 0.007 & $0.188 * * *$ & 0.006 & $-0.202 * * *$ \\
\hline $\mathrm{N}$ & $(0.015)$ & $(0.052)$ & $(0.017)$ & 133 \\
\hline $\begin{array}{l}\text { Pre-expansion proportion in } \\
\text { the expansion state group }\end{array}$ & 0.114 & 133 & 0.109 & 133 \\
\hline $\begin{array}{l}\text { No more than 35\% missing } \\
\text { in any year }\end{array}$ & 0.021 & 0.186 & -0.014 & 0.591 \\
\hline $\mathrm{N}$ & $(0.017)$ & $0.127 * *$ & $(0.030)$ & $-0.134 * * *$ \\
\hline
\end{tabular}

Notes: All models estimated with OLS and control for state demographics, state fixed effects, and year fixed effects. Standard errors are clustered at the state level and are reported in parentheses.

$* * * * * * *=$ statistically different from zero at the $1 \% ; 5 \% ; 10 \%$ level.

Supplementary Table 7B. Effect of ACA Medicaid expansions on payment source using alternative missingness thresholds: TEDS 2010-2015

\begin{tabular}{|c|c|c|c|c|}
\hline Outcome: & Private & Medicaid & Self-pay & $\begin{array}{c}\text { States and } \\
\text { localities }\end{array}$ \\
\hline $\begin{array}{l}\text { Pre-expansion proportion in } \\
\text { the expansion state group }\end{array}$ & 0.087 & 0.173 & 0.218 & 0.521 \\
\hline $\begin{array}{l}\text { No more than } 15 \% \text { missing } \\
\text { in any year }\end{array}$ & $\begin{array}{c}0.014 \\
(0.013)\end{array}$ & $\begin{array}{c}0.134 * * * \\
(0.034)\end{array}$ & $\begin{array}{c}-0.034 \\
(0.026)\end{array}$ & $\begin{array}{c}-0.114 * * \\
(0.045)\end{array}$ \\
\hline $\mathrm{N}$ & 140 & 140 & 140 & 140 \\
\hline $\begin{array}{l}\text { Pre-expansion proportion in } \\
\text { the expansion state group }\end{array}$ & 0.081 & 0.176 & 0.199 & 0.544 \\
\hline $\begin{array}{l}\text { No more than } 35 \% \text { missing } \\
\text { in any year }\end{array}$ & $\begin{array}{c}0.013 \\
(0.011)\end{array}$ & $\begin{array}{c}0.114 * * * \\
(0.034)\end{array}$ & $\begin{array}{l}-0.024 \\
(0.024)\end{array}$ & $\begin{array}{c}-0.103 * * \\
(0.041)\end{array}$ \\
\hline $\mathrm{N}$ & 157 & 157 & 157 & 157 \\
\hline
\end{tabular}

Notes: All models estimated with OLS and control for state demographics, state fixed effects, and year fixed effects.

Standard errors are clustered at the state level and are reported in parentheses.

$* * * ; * ; *=$ statistically different from zero at the $1 \% ; 5 \% ; 10 \%$ level. 
Supplementary Table 8. Conditional-on-positive analysis for insurance status and payment source: TEDS 2010-2015

\begin{tabular}{lcc}
\hline \hline Outcome: & $\begin{array}{c}\text { Missing } \leq \mathbf{2 5 \%} \\
\text { insurance status }\end{array}$ & $\begin{array}{c}\text { Missing } \leq \mathbf{2 5 \%} \\
\text { payment source }\end{array}$ \\
\hline $\begin{array}{l}\text { Pre-expansion proportion in the expansion state } \\
\text { group }\end{array}$ & 0.670 & 0.602 \\
\hline DD & 0.053 & 0.027 \\
& $(0.059)$ & $(0.035)$ \\
\hline $\mathrm{N}$ & 299 & 299 \\
\hline
\end{tabular}

Notes: Outcome is indicator variable coded one if a state has $>25 \%$ missing information in a given year, zero otherwise. We have also estimated comparable models in which the outcome is the share missing insurance and payment information. Results are similar and available on request. All models estimated with OLS and control for state demographics, state fixed effects, and year fixed effects. Standard errors are clustered at the state level and are reported in parentheses.

$* * * ; * ; *=$ statistically different from zero at the $1 \% ; 5 \% ; 10 \%$ level.

Supplementary Table 9A. Effect of ACA Medicaid expansions on insurance status using the wild-cluster bootstrap for inference: TEDS 2010-2015

\begin{tabular}{lcccc}
\hline \hline Outcome: & Private & Medicaid & Other insurance & Uninsured \\
\hline $\begin{array}{l}\text { Pre-expansion proportion in } \\
\text { the expansion state group }\end{array}$ & 0.114 & 0.186 & 0.109 & 0.591 \\
\hline DD & & & & \\
& 0.027 & $0.120^{* * *}$ & 0.016 & $-0.163^{* * *}$ \\
\hline $\mathrm{N}$ & $(1.459)$ & $(3.141)$ & $(1.040)$ & $(-4.197)$ \\
\hline
\end{tabular}

Notes: All models estimated with OLS and control for state demographics, state fixed effects, and year fixed effects. Insurance state sample includes the following states: $\mathrm{AK}, \mathrm{AL}, \mathrm{AR}, \mathrm{CO}, \mathrm{DC}, \mathrm{DE}, \mathrm{HI}, \mathrm{IA}, \mathrm{IL}, \mathrm{IN}, \mathrm{KS}, \mathrm{KY}, \mathrm{MA}, \mathrm{MD}$, ME, MO, MT, ND, NE, NH, NJ, NV, OR, PA, SC, SD, TN, TX, and UT. $t$-statistics are calculated using a wild cluster bootstrap following Cameron et al (2015) and are reported in parentheses.

$* * * ; * ; *=$ statistically different from zero at the $1 \% ; 5 \% ; 10 \%$ level.

Supplementary Table 9B. Effect of ACA Medicaid expansions on payment source using the wild-cluster bootstrap for inference: TEDS 2010-2015

\begin{tabular}{|c|c|c|c|c|}
\hline Outcome: & Private & Medicaid & Self-pay & $\begin{array}{c}\text { States and } \\
\text { localities }\end{array}$ \\
\hline $\begin{array}{l}\text { Pre-expansion proportion in } \\
\text { the expansion state group }\end{array}$ & 0.087 & 0.173 & 0.109 & 0.521 \\
\hline $\mathrm{DD}$ & $\begin{array}{c}0.030 * * * \\
(2.573)\end{array}$ & $\begin{array}{l}0.137 * * * \\
(2.836) \\
\end{array}$ & $\begin{array}{c}-0.015 \\
(-0.494)\end{array}$ & $\begin{array}{c}-0.153 * * * \\
(-2.700)\end{array}$ \\
\hline $\mathrm{N}$ & 145 & 145 & 145 & 145 \\
\hline
\end{tabular}

Notes: All models estimated with OLS and control for state demographics, state fixed effects, and year fixed effects. Payment source state sample includes the following states: AK, AR, CO, DC, HI, IA, ID, KS, KY, MO, MS, MT, $\mathrm{ND}, \mathrm{NE}, \mathrm{NH}, \mathrm{NJ}, \mathrm{NV}, \mathrm{OH}, \mathrm{PA}, \mathrm{RI}, \mathrm{SC}, \mathrm{SD}, \mathrm{TX}, \mathrm{UT}$, and VT. $t$-statistics are calculated using a wild cluster bootstrap following Cameron et al (2015) and are reported in parentheses.

$* * * ; * * * *=$ statistically different from zero at the $1 \% ; 5 \% ; 10 \%$ level. 
Supplementary Table 10. Effect of ACA Medicaid expansions on prescription medications financed by Medicaid reimbursements per 100,000 non-elderly adults: SDUD 2011-2015

\begin{tabular}{lccc}
\hline \hline Outcome: & $\begin{array}{c}\text { Total } \\
\text { reimbursements }\end{array}$ & $\begin{array}{c}\text { Medicaid } \\
\text { reimbursements }\end{array}$ & $\begin{array}{c}\text { Non-Medicaid } \\
\text { reimbursements }\end{array}$ \\
\hline $\begin{array}{l}\text { Pre-expansion mean in the expansion } \\
\text { state group }\end{array}$ & $\$ 109,861$ & $\$ 108,348$ & $\$ 1,513$ \\
\hline DD & $\$ 38,369 * * *$ & $\$ 38,568 * * *$ & $-\$ 199.013$ \\
& $(13940.659)$ & $(13916.604)$ & $(168.124)$ \\
\hline N & 1016 & 1016 & 1016 \\
\hline
\end{tabular}

Notes: All models estimated with OLS and control for state demographics, state fixed effects, and period fixed effects. Standard errors are clustered at the state level and are reported in parentheses.

$* * * ; * * * *=$ statistically different from zero at the $1 \% ; 5 \% ; 10 \%$ level.

Supplementary Table 11A. Effect of ACA Medicaid expansions on exogenous patient characteristics: TEDS 2010-2015

\begin{tabular}{lcccccc}
\hline \hline $\begin{array}{l}\text { Outcome: } \\
\text { Male }\end{array}$ & $\begin{array}{c}35+ \\
\text { years }\end{array}$ & White & $\begin{array}{c}\text { African } \\
\text { American }\end{array}$ & $\begin{array}{c}\text { Other } \\
\text { race }\end{array}$ & Hispanic \\
\hline $\begin{array}{l}\text { mean in the } \\
\text { expansion state }\end{array}$ & 0.646 & 0.448 & 0.676 & 0.123 & 0.103 & 0.100 \\
group & & & & & & \\
\hline DD & & & & & & \\
& 0.005 & 0.003 & $-0.016^{* *}$ & 0.003 & 0.009 & 0.004 \\
& $(0.006)$ & $(0.006)$ & $(0.007)$ & $(0.004)$ & $(0.006)$ & $(0.005)$ \\
\hline Observations & 299 & 299 & 299 & 299 & 299 & 299 \\
\hline
\end{tabular}

Notes: All models estimated with OLS and control for state demographics, state fixed effects, and year fixed effects. Standard errors are clustered at the state level and are reported in parentheses.

$* * * ; * ; *=$ statistically different from zero at the $1 \% ; 5 \% ; 10 \%$ level.

Supplementary Table 11B. Effect of ACA Medicaid expansions on endogenous patient characteristics: TEDS 2010-2015

\begin{tabular}{lcccc}
\hline \hline Outcome: & $\begin{array}{c}\text { Drug primary } \\
\text { substance }\end{array}$ & $\begin{array}{c}\text { Opioid primary } \\
\text { substance }\end{array}$ & $\begin{array}{c}\text { No prior } \\
\text { admission }\end{array}$ & $\begin{array}{c}\text { Criminal justice } \\
\text { system referral }\end{array}$ \\
\hline $\begin{array}{l}\text { Pre-expansion mean in } \\
\text { the expansion state }\end{array}$ & 0.576 & 0.289 & 0.387 & 0.357 \\
group & & & & \\
\hline DD & -0.001 & 0.009 & $-0.031^{* *}$ & $(0.014)$ \\
\hline Observations & $(0.011)$ & $(0.014)$ & $293+$ & $(0.013)$ \\
\hline
\end{tabular}

Notes: All models control for state demographics, state fixed effects, and year fixed effects. Standard errors are clustered at the state level and are reported in parentheses.

†There is some missing data for the referral source item, thus we have a smaller sample size for this outcome. $* * *, * *, *=$ statistically different from zero at the $1 \%, 5 \%, 10 \%$ level. 
Supplementary Table 12. Effect of ACA Medicaid expansions on treatment setting: TEDS 2010-2015

\begin{tabular}{lcccc}
\hline \hline Outcome: & Detoxification & $\begin{array}{c}\text { Non-intensive } \\
\text { outpatient }\end{array}$ & $\begin{array}{c}\text { Intensive } \\
\text { outpatient }\end{array}$ & Residential \\
\hline $\begin{array}{l}\text { Pre-expansion mean in } \\
\text { the expansion state }\end{array}$ & 0.192 & 0.544 & 0.122 & 0.143 \\
group & & & & 0.013 \\
\hline DD & -0.013 & -0.009 & 0.009 & $(0.011)$ \\
\hline Observations & $(0.018)$ & $(0.020)$ & $(0.012)$ & 299 \\
\hline
\end{tabular}

Notes: All models control for state demographics, state fixed effects, and year fixed effects. Standard errors are clustered at the state level and are reported in parentheses.

$* * *, * * *=$ statistically different from zero at the $1 \%, 5 \%, 10 \%$ level. 
Supplementary Table 13A. Effect of ACA Medicaid expansions on admissions per 100,000 non-elderly adults using the TEDS insurance and payment samples of states: TEDS 2010-2015

\begin{tabular}{lcc}
\hline \hline Sample: & Insurance states & Payment states \\
\hline $\begin{array}{l}\text { Pre-expansion mean in the expansion state } \\
\text { group }\end{array}$ & 1028 & 1045 \\
\hline DD & & $192.067 * *$ \\
& 94.746 & $(88.305)$ \\
\hline $\mathrm{N}$ & $(87.593)$ & 145 \\
\hline
\end{tabular}

Notes: The outcome variable is the number of admissions per 100,000 non-elderly adults. All models estimated with OLS and control for state demographics, state fixed effects, and year fixed effects. Insurance state sample includes the following states: AK, AL, AR, CO, DC, DE, HI, IA, IL, IN, KS, KY, MA, MD, ME, MO, MT, ND, NE, NH, NJ, NV, OR, PA, SC, SD, TN, TX, and UT. Payment source state sample includes the following states: AK, AR, CO, DC, HI, IA, ID, KS, KY, MO, MS, MT, ND, NE, NH, NJ, NV, OH, PA, RI, SC, SD, TX, UT, and VT.

Standard errors are clustered at the state level and are reported in parentheses.

$* * * ; * ; *=$ statistically different from zero at the $1 \% ; 5 \% ; 10 \%$ level.

Supplementary Table 13B. Effect of ACA Medicaid expansions on prescription medications financed by Medicaid per 100,000 non-elderly adults using the TEDS insurance and payment samples of states: SDUD 2011-2015

\begin{tabular}{lcc}
\hline \hline Sample: & Insurance states & Payment states \\
\hline Pre-expansion mean in the expansion state group & 572 & 839 \\
\hline DD & $255.108^{* *}$ & $384.816^{* *}$ \\
& $(105.003)$ & $(147.944)$ \\
\hline N & 576 & 496 \\
\hline
\end{tabular}

Notes: All models estimated with OLS and control for state demographics, state fixed effects, and period fixed effects. Insurance state sample includes the following states: AK, AL, AR, CO, DC, DE, HI, IA, IL, IN, KS, KY, MA, MD, ME, MO, MT, ND, NE, NH, NJ, NV, OR, PA, SC, SD, TN, TX, and UT. Payment source state sample includes the following states: AK, AR, CO, DC, HI, IA, ID, KS, KY, MO, MS, MT, ND, NE, NH, NJ, NV, OH, PA, RI, SC, SD, TX, UT, and VT. Standard errors are clustered at the state level and are reported in parentheses. $* * * ; * * ;=$ statistically different from zero at the $1 \% ; 5 \% ; 10 \%$ level. 